\title{
Otimização de portfólio: Métrica do risco com espaço objetivo aumentado
}

\author{
Portfolio optimization: Risk metric with increased objective space \\ Optimización de lo portfolio: Métrica de riesgo con mayor espacio objetivo
}

Recebido: 18/04/2021 | Revisado: 24/04/2021 | Aceito: 29/04/2021 | Publicado: 13/05/2021

\author{
Marcos Huber Mendes \\ ORCID: https://orcid.org/0000-0002-7203-3552 \\ Pontifícia Universidade Católica do Rio de Janeiro, Brasil \\ E-mail: hubermendes@decisionsupport.com.br \\ Reinaldo Castro Souza \\ ORCID: https://orcid.org/0000-0002-0210-3703 \\ Pontifícia Universidade Católica do Rio de Janeiro, Brasil \\ E-mail: reinaldo@puc-rio.br \\ Marco Aurélio Sanfins \\ ORCID: https://orcid.org/0000-0001-9807-1541 \\ Universidade Federal Fluminense, Brasil \\ E-mail: marcosanfins@id.uff.br
}

\begin{abstract}
Resumo
O modelo de portfólio EV eficiente de Markowitz, dado um retorno mínimo requerido, minimiza a variância do portfólio, uma métrica do risco de tendência central calculada pelo método estatístico de concentração de dados, e assim utiliza uma fórmula literal permitindo a solução da otimização por um algoritmo quadrático, exigindo pouco consumo computacional. As evoluções do modelo de Markowitz para métricas assimétricas do risco, minimizam e/ou maximizam o risco, abaixo e/ou acima de um alvo t, como o downside risk, o mean-separated target deviations, o value at risk e o conditional value at risk, porém, não permitem utilizar uma fórmula literal para solução da otimização, transformada em um algoritmo não suave, com solução complexa e maior consumo computacional. $\mathrm{O}$ aspecto relevante do modelo de Markowitz foi mostrar que o mais importante não é o risco do ativo mas a contribuição que cada ativo fornece para o risco do portfólio, que depende das interrelações entre os ativos, a covariância do portfólio. Estendendo o raciocínio como contribuição original e relevante, o artigo apresenta uma nova métrica assimétrica do risco, com maior detalhamento das interrelações entre os ativos, aumentando o espaço objetivo da otimização, com maior número de parâmetros otimizados, possibilitando a busca por melhores resultados e utilizando uma expressão literal permitindo solução por um algoritmo não linear, menos complexo que o algoritmo não suave. A análise bibliométrica realizada demonstra a originalidade da evolução do modelo de Markowitz para métricas assimétricas do risco, apresentando fórmula literal para solução e com espaço objetivo aumentado.
\end{abstract}

Palavras-chave: Métrica do risco; Espaço objetivo aumentado; Métrica estatística eficiente; Novas métricas para eficiência do portfólio; Otimização de portfólio.

\begin{abstract}
Markowitz's efficient EV portfolio model, given a minimum required return, minimizes the portfolio variance, a central trend risk metric calculated by the statistical method of data concentration, and thus uses a literal formula allowing the optimization solution by a quadratic algorithm, requiring little computational consumption. The evolution of the Markowitz model for asymmetric risk metrics, minimizes and/or maximizes risk, below and/or above a target $\mathbf{t}$, such as downside risk, mean-separated target deviations, value at risk and conditional value at risk, however, do not allow the use of a literal formula for the optimization solution, transformed into a non-smooth algorithm, with a complex solution and greater computational consumption. The relevant aspect of the Markowitz model was to show that the most important is not the risk of the asset, but the contribution that each asset provides to the risk of the portfolio, which depends on the interrelationships between the assets, the covariance of the portfolio. Extending the reasoning as an original and relevant contribution, the article presents a new asymmetric risk metric, with greater detail of the interrelationships between assets, increasing the objective space of the optimization, with a greater number of optimized parameters, enabling the search for better results and using a literal expression allowing solution by a non-linear algorithm, less complex than the non-smooth algorithm. The bibliometric analysis carried out demonstrates the originality of the evolution of the Markowitz model for asymmetric risk metrics, presenting a literal formula for solution and with increased objective space.
\end{abstract}

Keywords: Risk metric; Increased objective space; Efficient statistical metric; New metrics for portfolio efficiency; Portfolio optimization. 


\section{Resumen}

El modelo de portfolio EV eficiente de Markowitz, dado un rendimiento mínimo requerido, minimiza la varianza de la cartera, una métrica del riesgo de tendencia central calculada por el método estadístico de concentración de datos y, por lo tanto, utiliza una fórmula literal que permite la solución de la optimización mediante un algoritmo cuadrático, lo que requiere poco consumo computacional. La evolución del modelo de Markowitz para métricas asimétricas de riesgo, minimiza y/o maximiza el riesgo, por debajo y/o por encima de un objetivo $\mathbf{t}$, como el downside risk, el mean-separated target deviations, el value at risk and el conditional value at risk, sin embargo, no permiten el uso de una fórmula literal para la solución de la optimización, transformada en un algoritmo no suave, con una solución compleja y mayor consumo computacional. El aspecto relevante del modelo de Markowitz fue mostrar que lo más importante no es el riesgo del activo sino la contribución que cada activo proporciona al riesgo de lo portfolio, que depende de las interrelaciones entre los activos, la covarianza de lo portfolio. Ampliando el razonamiento como un aporte original y relevante, el artículo presenta una nueva métrica asimétrica de riesgo, con mayor detalle de las interrelaciones entre activos, aumentando el espacio objetivo de optimización, con un mayor número de parámetros optimizados, posibilitando la búsqueda de mejores resultados y utilizando una expresión literal que permite la solución mediante un algoritmo no lineal, menos complejo que el algoritmo no suave. El análisis bibliométrico realizado demuestra la originalidad de la evolución del modelo de Markowitz para métricas asimétricas de riesgo, presentando una fórmula literal de solución y con mayor espacio objetivo.

Palabras clave: Métrica de riesgo; Mayor espacio objetivo; Métrica estadística eficiente; Nuevas métricas para la eficiencia de lo portfolio; Optimización de portfolio.

\section{Introdução}

O modelo de otimização de portfólio EV de Markowitz, H., M. (1952) (EV), pelo seu apelo prático, devido à utilização da média e da variância, devido à facilidade de utilização de suas propriedades no desenvolvimento de modelos teóricos, principalmente quando se assume distribuições da família exponencial como a normal (gaussiana) ou a log-normal e devido à solução do algoritmo de otimização por um modelo quadrático, com necessidade reduzida de consumo computacional, foi utilizado em diversas áreas além da seleção de portfólios de ativos de investimento da bolsa de valores, como por exemplo, na seleção de portfólios de contratos de energia elétrica Arce, P., E., B., Arce, A., S., E. \& Carneiro A., A., F., M. (2014), na seleção de portfólios para minimizar a variabilidade da energia elétrica eólica agregada em grandes regiões da Europa, Tejeda, C. et al.. (2017), na seleção de portfólios de projetos de óleo e gás, considerando como ativos a distribuição de valores presentes líquidos, Bulai, V. \& Horobeț, A. (2018), na seleção de portfólios de usinas de energia Glensk, B. \& Madlener, R. (2018), ou ainda na estratégia de gerenciamento de portfólios de geração de gás com base em opções de derivativos financeiros, Lai S., Tao, Y., Qiu, J. \& Zhao, J. (2019).

A formulação matemática do modelo de portfólios EV Eficientes de Markowitz, H., M. (1952) considera quatro premissas básicas: i) vendas a descoberto não são permitidas, ou seja, a fração dos recursos a investir em cada ativo é maior ou igual a zero; ii) a soma das frações a investir é igual ao capital disponível para investimento, ou seja, a soma das frações dos recursos investidas em cada ativo é igual a unidade; iii) os ativos são correlacionados mas não perfeitamente correlacionados, implicando em que a diversificação pode reduzir mas não eliminar o risco; e iv) a separação dos portfólios eficientes dos não eficientes. Os portfólios eficientes consistem de portfólios com menor incerteza do que qualquer outro portfólio, para um dado valor $\mathrm{R} *$ de mínimo retorno requerido (MRR).

Com base nestas premissas, o modelo de Markowitz, H., M. (1952) procura encontrar o portfólio eficiente que oferece o menor risco para cada nível pré-definido do mínimo retorno requerido. O risco é medido pela variância ou desvio padrão dos retornos dos ativos do portfólio. O conjunto de portfólios eficientes para diferentes níveis de mínimo retornos requeridos constitui a Fronteira Eficiente (FE), que limita os portfólios viáveis. 
O modelo de otimização de portfólios EV eficiente de Markowitz, H., M. (1952) pode ser representado como

$$
\begin{aligned}
& \underset{X}{\operatorname{Min}} V\left(R_{p}\right)=X^{\prime} Q X \\
& \text { Sujeito a: } E\left(R_{p}\right)=\widehat{R^{\prime}} X \geq R^{*}, x_{i} \geq 0, \text { e } \quad \sum_{1=1}^{n} x_{i}=1 ;
\end{aligned}
$$

sendo a minimização de $\mathbf{V}\left(\boldsymbol{R}_{\boldsymbol{p}}\right)$ realizada pela variação do vetor de pesos $\boldsymbol{X}$.

Onde o risco ou variância do portfólio $\mathbf{V}\left(\boldsymbol{R}_{\boldsymbol{p}}\right)$ pode ser calculado como $\mathbf{V}\left(\boldsymbol{R}_{\boldsymbol{p}}\right)=\boldsymbol{X}^{\prime} \boldsymbol{Q} \boldsymbol{X}$, onde $\boldsymbol{Q}$ é a matriz de variância-covariância dos ativos $\boldsymbol{A}_{\boldsymbol{i}}$ do portfólio em questão e a minimização de $\mathbf{V}\left(\boldsymbol{R}_{\boldsymbol{p}}\right)$ é realizada pela variação do vetor de pesos $\boldsymbol{X}$. O retorno esperado do portfólio pode ser calculado como $\boldsymbol{E}\left(\boldsymbol{R}_{\boldsymbol{p}}\right)=\widehat{\boldsymbol{R}^{\prime}} \boldsymbol{X}$ onde $\widehat{\boldsymbol{R}}$ é o vetor dos retornos esperados $\overline{\boldsymbol{r}}_{\mathrm{i}}$ dos ativos $\boldsymbol{A}_{\boldsymbol{i}}$ do portfólio em questão. Considerando como $\mathbf{R}^{*}$ o mínimo retorno requerido do portfólio.

O modelo de otimização de portfólio EV eficiente de Markowitz, H., M. (1952), utiliza o retorno médio do portfólio e uma métrica do risco de tendência central, a variância, o que permite que se calcule o retorno esperado e a variância do portfólio por fórmulas literais que consideram o valor esperado e a variância e covariância dos $\mathbf{n}$ ativos que compõem o portfólio o que permite a solução do modelo por um algoritmo de otimização quadrático, com baixo consumo computacional e apresentando um ótimo global.

Para resolver o modelo de otimização, se utiliza fórmulas empíricas análogas as do retorno médio, da variância e da covariância entre os ativos. Considerando amostras com $\mathbf{z}$ observações de cada ativo $\boldsymbol{A}_{\boldsymbol{i}}$, se obtém:

$$
\begin{aligned}
& \hat{\bar{r}}=\left(\sum_{s=1}^{\mathrm{z}} \mathbf{r}_{\mathrm{is}}\right) / \mathrm{z} \\
& \text { - } S_{i j}=\sum_{\mathrm{s}=1}^{\mathrm{z}} \sum_{\mathrm{s}=1}^{\mathrm{z}}\left(\mathbf{r}_{\mathrm{is}}-\overline{\boldsymbol{r}}_{\mathrm{i}}\right)\left(\mathbf{r}_{\mathrm{js}}-\overline{\boldsymbol{r}}_{j}\right) /(\mathrm{z}-1) \\
& \text { - } S_{i i}=\sum_{\mathrm{i}=1}^{\mathrm{z}}\left(\mathbf{r}_{\mathrm{is}}-\overline{\mathbf{r}}_{\mathrm{i}}\right)^{2} /(\mathrm{z}-1)
\end{aligned}
$$

Estudos como o de Markowitz H., M. (1959), Bawa, V.S. \& Lindenberg, E.B. (1977), Fishburn, P.C. (1977), Holthausen D.M. (1981), e Kang, T., Brorsen B.W. \& Adam, B.D. (1996) estenderam o conceito do modelo de otimização de portfólios EV eficiente (EV) proposto por Markowitz, H., M. (1952) ao associar diferentes métricas como medida de posição e medida de dispersão do portfólio. Especificamente, Markowitz H., M. (1959) com o conceito de semi-variância abaixo da média, Bawa, V.S. \& Lindenberg, E.B. (1977) com o conceito de momento parcial abaixo da média, Fishburn, P.C. (1977) estendeu o conceito de semi-variância abaixo da média para o momento parcial abaixo de um retorno alvo ou um mínimo retorno aceitável (MRA), Holthausen D.M. (1981) utilizou o conceito de lower partial moment para medir o risco e considerou o retorno como uma função do upper partial moment. O modelo Mean-Separated Target Deviations de Kang, T., Brorsen B.W. \& Adam, B.D. (1996) considerou o risco como uma métrica conjunta do desvio abaixo e acima de um retorno alvo usando o conceito de momento parcial não central ou desvio em torno de um retorno alvo $\mathbf{t}$, generalizando grande parte dos modelos anteriores. Estas métricas estendem o modelo original para a consideração da assimetria, porém, resultam em métodos de otimização extremamente complexos para época.

Rom, B.M. \& Ferguson K.W. (1993) desenvolveram algoritmos, pelo The Pension Research Institute, para otimização do Downside Risk, ou risco abaixo de um retorno alvo, e a partir do seu desenvolvimento diferentes modelos e métricas assimétricas do risco foram apresentados para solucionar o problema de otimização de portfólios. Além do Downside Risk, entre as métricas assimétricas do risco desenvolvidas, se pode citar métricas como as do modelo de Mean-Separated Target Deviations, 
do Value at Risk e do Conditional Value at Risk. Porém, estas e diversas outras métricas assimétricas do risco desenvolvidas não apresentam um espaço objetivo aumentado. Conforme será verificado na análise bibliométrica ainda não foi, até a presente data, apresentada uma métrica do risco com espaço objetivo aumentado, ou seja, com um maior número de parâmetros a otimizar, de forma a permitir, ao algoritmo de solução, a busca por melhores resultados e utilizando uma expressão literal permitindo solução por um algoritmo não linear, que pode convergir para um ótimo global.

O modelo de seleção de portfólios $\mathbf{E V}$ apresenta uma forma literal para resolver a variância do portfólio em função da variância dos ativos o que permite a solução do algoritmo de otimização por um modelo quadrático, com necessidade reduzida de consumo computacional e apresentando um ótimo global. Já os atuais modelos com métricas assimétricas do risco não apresentam uma forma literal para resolver a variância do portfólio em função da variância dos ativos, o que transforma a otimização em modelos não suaves, de solução complexa, com aumento do consumo computacional e apresentando apenas uma solução viável ou um ótimo local.

Os atuais modelos com métrica assimétrica do risco, pelo desvio em torno de um alvo $\mathbf{t}$, não assumem uma forma quadrática e não possibilitam a construção do momento parcial do portfólio a partir dos $\mathbf{n}$ momentos parciais e momentos parciais co-variados de ordem dois dos ativos. De forma geral, não se tem uma forma literal que permita simplificar a complexidade computacional de um modelo descontínuo e não linear. Isto significa que, como usualmente utilizado nos modelos com métricas assimétricas do risco, se tem que utilizar dados empíricos para resolver o algoritmo do modelo de otimização, sem utilizar uma expressão literal, e que o algoritmo de otimização se apresenta como um problema de otimização não suave com solução complexa, que aumenta o consumo computacional, e que somente fornece uma solução viável ou um ótimo local.

$\mathrm{O}$ artigo apresenta uma nova métrica assimétrica do risco, com um maior detalhamento das interrelações entre os ativos, aumentando o espaço objetivo da otimização por utilizar um maior número de componentes na equação, o que acarreta um maior número de parâmetros a serem otimizados e a possibilidade de busca por melhores resultados. A nova métrica assimétrica do risco apresenta uma expressão literal, que utiliza as métricas do risco dos ativos do portfólio, para solução do algoritmo de otimização, permitindo a solução por um algoritmo não linear que é menos complexo que o algoritmo não suave e que pode apresentar um ótimo global. Para demonstrar a originalidade da evolução do modelo EV de Markowitz, H., M. (1952) para uma métrica assimétrica do risco apresentando um espaço objetivo aumentado e uma expressão literal para solução do algoritmo de otimização, a bibliometria realizada na próxima seção apresenta a análise dos resultados de forma que se possa concluir se existe algum documento a respeito de métrica do risco que apresente seus resultados na forma de uma métrica assimétrica do risco com espaço objetivo aumentado e utilizando uma formula literal para solução do algoritmo de otimização, e caso existam como são suas formulações. 


\section{Análise Bibliométrica}

A análise bibliométrica tem como objetivo determinar a originalidade da nova métrica assimétrica do risco que será definida na Seção 4. A revisão da literatura foi realizada a partir do banco de dados da Scopus e da Web of Science, utilizando somente artigos revisados por pares, sendo a pesquisa realizada para o período de primeiro de janeiro de 2010 a março de 2021 . Foram empregadas técnicas de bibliometria conforme Domingues, M. A. (2018) no artigo Mapeamento da Ciência com o Pacote R Bibliometrix: Uma aplicação no estudo de Empreendedorismo Acadêmico. Foram utilizados o software R com o pacote Bibliometrix, Aria, M. \& Cuccurullo, C. (2017). A bibliometria é uma técnica quantitativa e estatística capaz de medir índices de produção e conhecimento científico, Pritchard, A. (1969). Os resultados e sua análise são apresentados a seguir.

O banco de dados da Scopus é o maior banco de dados de resumos e citações da literatura revisada por pares, com ferramentas bibliométricas para monitorar, analisar e visualizar a pesquisa.

Segundo informação solicitada a Scopus esta dispõe atualmente de:

- $\quad 80$ milhões de resultados vindos de 24.272 títulos seriais cobertos, 101.000 conferências e 230.000 livros;

- $\quad$ Conteúdo publicado por mais de 5000 editores em 105 países e mais de 40 idiomas;

- Atualizada diariamente - aproximadamente 10.000 novos documentos indexados por dia;

- $\quad$ 10.807.000 documentos de acesso aberto;

- Cobertura de "articles in press" de mais de 8075 títulos.

Segundo o site da Web of Science esta dispõe de "estatísticas de tendências científicas extraídas de mais de 12 milhões de artigos de mais de 12.000 periódicos globais, o Essential Science Indicators oferece a cobertura detalhada que seja necessária para efetivamente analisar e comparar o desempenho da pesquisa, identificar tendências significativas, classificar os melhores desempenhos e avaliar funcionários e colaboradores em potencial”. Com base em um arquivo contínuo de 10 anos, os indicadores Essential Science são atualizados a cada dois meses.

As pesquisas bibliométricas foram realizadas na Scopus e na Web of Science e a chave de busca foi orientada de acordo com o artigo A comprehensive review of deterministic models and applications for mean-variance portfolio optimization, Kalayci C.B.; Ertenlice, O. \& Akbaya, M.A. (2019). A pesquisa foi realizada conforme a chave de pesquisa apresentada abaixo e é uma pesquisa específica sobre as extensões do modelo $\mathbf{E V}$ para diferentes métricas do risco.

- Chave de pesquisa: TITLE-ABS-KEY (Portfolio AND ((selection OR management OR optimization) AND (mean OR variance)) AND (assessment OR metrics OR measures OR estimation)) AND PUBYEAR > 2009 
A pesquisa realizada na Scopus retornou uma base de dados com 572 documentos e a pesquisa realizada na Web of Science retornou uma base de dados com 567 documentos. Para as duas pesquisas a análise bibliométrica apresentará como resultado:

- O sumário da pesquisa bibliométrica;

- A tabela de frequência das cinquenta keywords mais frequentes e o resultado da frequência para palavras chaves de interesse para métricas do risco nas duzentas keywords mais frequentes;

- O gráfico de Co-occurrence para as trinta e cinco keywords mais frequentes e uma análise do gráfico considerando o filtro pela keyword risk measure. O gráfico de Co-occurrence network é uma nova forma de acoplamento de documentos definida como a frequência com que documentos são citados em conjunto por outro documento. A frequência de co-citação de dois artigos científicos pode ser determinada comparando a citação de documentos na base de dados resultante da pesquisa realizada e contando entradas idênticas;

- A classificação dos resultados conjuntos dos documentos nas duas bases de dados, uma da Scopus e outra da Web of Science, nos campos de keywords, keywords plus (keywords das referências), abstract e title, filtrados especificamente pelas as keyword assessment, metrics, measures e estimation.

A análise dos resultados será realizada para se concluir se existe algum documento a respeito de métrica do risco que apresente seus resultados na forma de uma métrica assimétrica do risco com espaço objetivo aumentado e utilizando uma formula literal para solução do algoritmo de otimização, e caso existam como são suas formulações.

Para as pesquisas na Scopus e na Web of Science, em conjunto, a Tabela 1 a seguir apresenta o sumário das pesquisas realizadas. 
Tabela 1: Sumário das pesquisas na Scopus e na Web of Science.

\begin{tabular}{|c|c|c|}
\hline $\begin{array}{l}\text { Descrição } \\
\text { PRINCIPAIS NFORMAÇÕES }\end{array}$ & $\begin{array}{c}\text { Resultados } \\
\text { Scopus }\end{array}$ & $\begin{array}{c}\text { Resultados } \\
\text { Web Of Science }\end{array}$ \\
\hline Intervalo de tempo & 2010:2021 & 2010:2020 \\
\hline FONTES (Jornais, livros, etc) & 322 & 295 \\
\hline Documentos & 572 & 567 \\
\hline Médiam de anos por publicação & 5.4 & 5.17 \\
\hline Média de citações por documentos & 8.691 & 8.84 \\
\hline Média de citações por ano por documento & 1.152 & 1.241 \\
\hline Referencias & 18029 & 17146 \\
\hline \multicolumn{3}{|l|}{ TIPOS de DOCUMENTOS } \\
\hline Artigos & 468 & 468 \\
\hline Artigos no prelo & 1 & - \\
\hline Livros & 2 & - \\
\hline Capítulo de Livro & 24 & - \\
\hline Artigo de Conferência & 67 & - \\
\hline Revisões de Conferência & 5 & - \\
\hline Erratas & 1 & - \\
\hline Revisões & 4 & - \\
\hline Artigo; acesso antecipado & - & 20 \\
\hline Artigo; apresentação de seminários & - & 9 \\
\hline Apresentação de seminários & - & 62 \\
\hline Revisão de artigos & - & 7 \\
\hline Revisões; acesso antecipado & - & 1 \\
\hline \multicolumn{3}{|l|}{ CONTEÚDO de DOCUMENTOS } \\
\hline Keywords Plus (ID) & 1711 & 864 \\
\hline Author's Keywords (DE) & 1497 & 1714 \\
\hline AUTORES & 1208 & 1089 \\
\hline Autores publicações & 1490 & 1422 \\
\hline Autores de documentos de autoria única & 72 & 75 \\
\hline Autores de documentos de autoria múltipla & 1136 & 1014 \\
\hline \multicolumn{3}{|l|}{ AUTORES COLABORAÇÃO } \\
\hline Documentos de autoria única & 86 & 86 \\
\hline Documentos por autor & 0.474 & 0.521 \\
\hline Autor por documentos & 2.11 & 1.92 \\
\hline Co-autor por documentos & 2.6 & 2.51 \\
\hline Índice de colaboração & 2.34 & 2.11 \\
\hline
\end{tabular}

Fonte: Dados da Scopus e da Web of Science elaborado pelo autor.

Na pesquisa da Scopus se percebe, entre outros, um total de 572 documentos, uma média de 8,691 citações por documentos e um total de 18029 referências. Na pesquisa da Web of Science se percebe, entre outros, um total de 567 documentos, uma média de 8,84 citações por documentos e um total de 17146 referências.

Para as pesquisas na Scopus e na Web of Science, em conjunto, a Tabela 2 a seguir apresenta a tabela de frequência das cinquenta keywords mais frequentes. 
Research, Society and Development, v. 10, n. 5, e47210515189, 2021

(CC BY 4.0) | ISSN 2525-3409 | DOI: http://dx.doi.org/10.33448/rsd-v10i5.15189

Tabela 2: Pesquisa na Scopus e na Web of Science cinquenta keywords mais frequentes.

\begin{tabular}{|c|c|c|}
\hline Terms & $\begin{array}{c}\text { Frequency } \\
\text { Scopus }\end{array}$ & $\begin{array}{c}\text { Frequency } \\
\text { Web of Science }\end{array}$ \\
\hline dynamic & - & 6 \\
\hline g11 & - & 12 \\
\hline management & - & 7 \\
\hline model & - & 9 \\
\hline programming & - & 11 \\
\hline selection & - & 13 \\
\hline portfolio optimization & 117 & 95 \\
\hline portfolio selection & 73 & 64 \\
\hline value-at-risk & 39 & 22 \\
\hline conditional value at risk & 31 & 30 \\
\hline mean-variance model & 30 & 14 \\
\hline risk management & 29 & 20 \\
\hline mean-variance optimization & 28 & 14 \\
\hline efficient frontier & 22 & 34 \\
\hline optimization & 20 & 30 \\
\hline mean-variance & 19 & 34 \\
\hline risk measure & 18 & 21 \\
\hline downside risk & 18 & 9 \\
\hline robust optimization & 16 & 8 \\
\hline asset allocation & 14 & 16 \\
\hline portfolio & 14 & 40 \\
\hline portfolio theory & 14 & 10 \\
\hline portfolios & 14 & 8 \\
\hline finance & 13 & 14 \\
\hline investment analysis & 13 & 8 \\
\hline transaction costs & 13 & 9 \\
\hline sharpe ratio & 12 & 10 \\
\hline mean-variance analysis & 11 & 14 \\
\hline entropy & 10 & 12 \\
\hline estimation risk & 10 & 12 \\
\hline genetic algorithm & 10 & 5 \\
\hline portfolio management & 10 & 9 \\
\hline portfolio choice & 8 & 10 \\
\hline estimation error & 7 & 8 \\
\hline portfolio construction & 7 & 4 \\
\hline skewness & 7 & 6 \\
\hline uncertain variable & 7 & 12 \\
\hline investment & 6 & 8 \\
\hline machine learning & 6 & 3 \\
\hline optimal portfolio selection & 6 & 5 \\
\hline particle swarm optimization & 6 & 3 \\
\hline risk & 6 & 19 \\
\hline variance & 6 & 8 \\
\hline covariance matrix & 5 & 5 \\
\hline credibility measure & 5 & 7 \\
\hline diversification & 5 & 3 \\
\hline dynamic programming & 5 & 6 \\
\hline expected shortfall & 5 & 5 \\
\hline forecasting & 5 & 6 \\
\hline linear programming & 5 & 5 \\
\hline markowitz & 5 & 6 \\
\hline parameter uncertainty & 5 & 7 \\
\hline multi-period portfolio selection & 4 & 7 \\
\hline semivariance & 4 & 8 \\
\hline uncertainty & 4 & 9 \\
\hline estimation & 3 & 7 \\
\hline mean-variance portfolio & 3 & 8 \\
\hline
\end{tabular}

Fonte: Dados da Scopus e da Web of Science elaborado pelo autor. 
Na Tabela 2 acima, das cinquenta mais frequentes keywords na pesquisa da Scopus e da Web of Science, em conjunto, as keywords mais frequentes relacionadas com métricas do risco ou com modelos que consideram a evolução do modelo de Markowizt, H., M. (1952) com novas métricas do risco são value-at-risk, conditional value at risk, mean-variance model, meanvariance optimization, mean-variance, risk measure, downside risk, robust optimization e sharpe ratio que apresentam respectivamente as frequências de 39, 31, 38, 28, 34, 21, 18, 16 e 12 ocorrências e as keywords, particle swarm optimization, variance, expected shortfall, semivariance e mean-variance portfolio, que apresentam respectivamente as frequências de $6,8,5$, 8 e 8 ocorrências. Nas duzentas mais frequentes keywords da pesquisa na Scopus e da pesquisa na Web of Science as demais keywords relacionadas com métricas do risco ou com modelos que consideram a evolução do modelo de Markowizt, H., M. (1952) com novas métricas do risco são um total de 18 keywords que apresentam frequências variando entre 6 e 3 ocorrências.

$\mathrm{Na}$ Tabela 2 acima e nas duzentas mais frequentes keywords da pesquisa na Scopus e da pesquisa na Web of Science não aparecem keywords relacionadas especificamente com a evolução do modelo de Markowizt, H., M. (1952) para métricas assimétricas do risco com resultados na forma de uma métrica assimétrica do risco com espaço objetivo aumentado e utilizando uma formula literal para solução do algoritmo de otimização.

Será apresentada agora para a pesquisa na Scopus, uma nova forma de acoplamento de documentos denominada cooccurrence network que é definida como a frequência com que documentos são citados em conjunto por outro documento. A frequência de co-citação de dois artigos científicos pode ser determinada comparando a citação de documentos na base de dados da Scopus e contando entradas idênticas. A rede de co-citação pelas trinta e cinco keywords mais frequentes da pesquisa na Scopus é apresentada abaixo na Figura 1. 
Research, Society and Development, v. 10, n. 5, e47210515189, 2021

(CC BY 4.0) | ISSN 2525-3409 | DOI: http://dx.doi.org/10.33448/rsd-v10i5.15189

Figura 1: Co-occurrence network das keywords da pesquisa na Scopus.

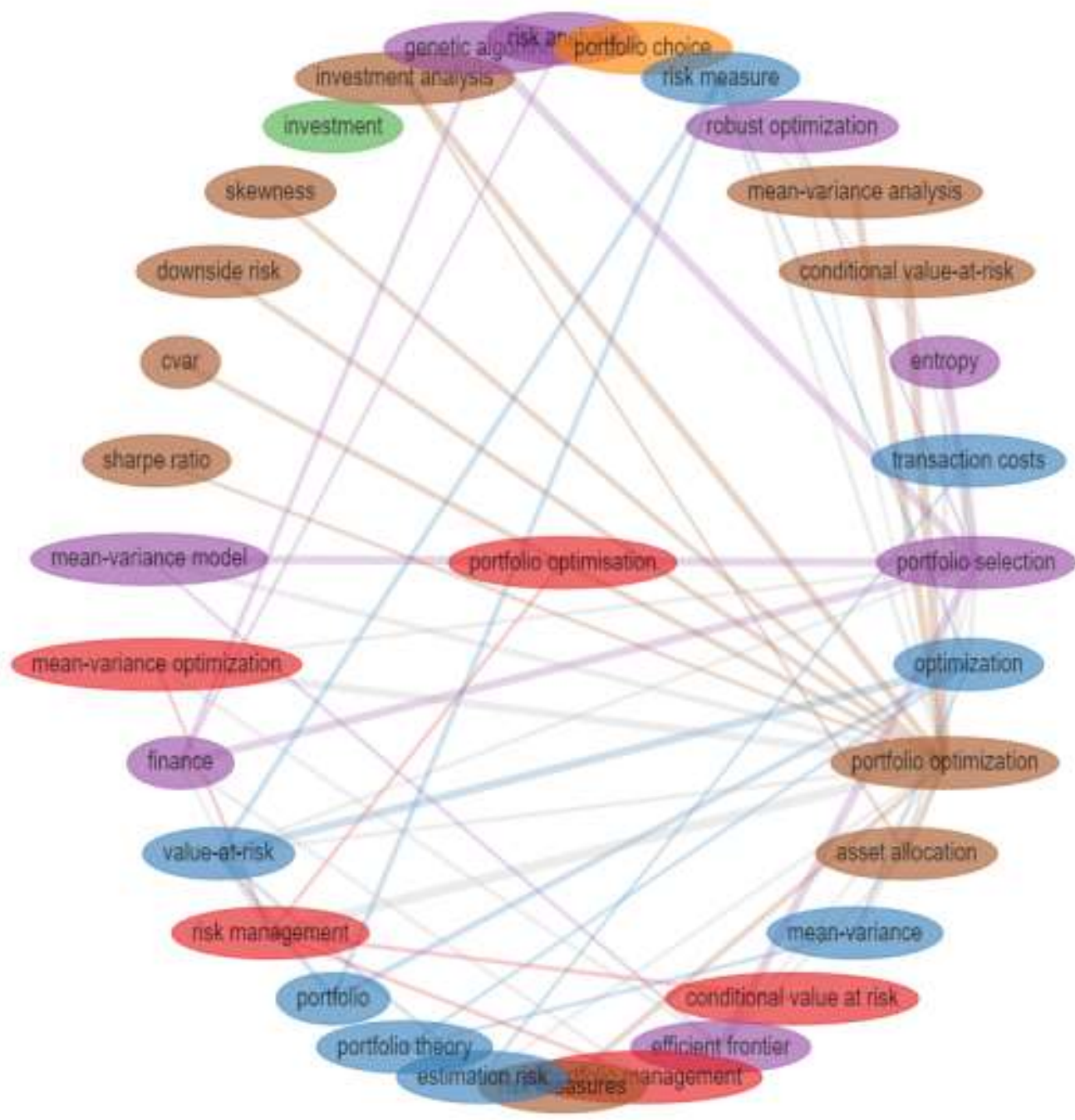

Fonte: Dados da Scopus elaborado pelo autor.

Na Figura 1 acima, para uma melhor visualização da rede de co-citação em relação à métricas do risco, foi aplicado um filtro para a keyword risk measure. Com a aplicação do filtro se pode verificar quais são as interrelações da keyword risk measure com as demais keywords, conforme a Figura 2 a seguir. 
Research, Society and Development, v. 10, n. 5, e47210515189, 2021

(CC BY 4.0) | ISSN 2525-3409 | DOI: http://dx.doi.org/10.33448/rsd-v10i5.15189

Figura 2: Co-occurrence network da pesquisa na Scopus com filtro para risk measure.

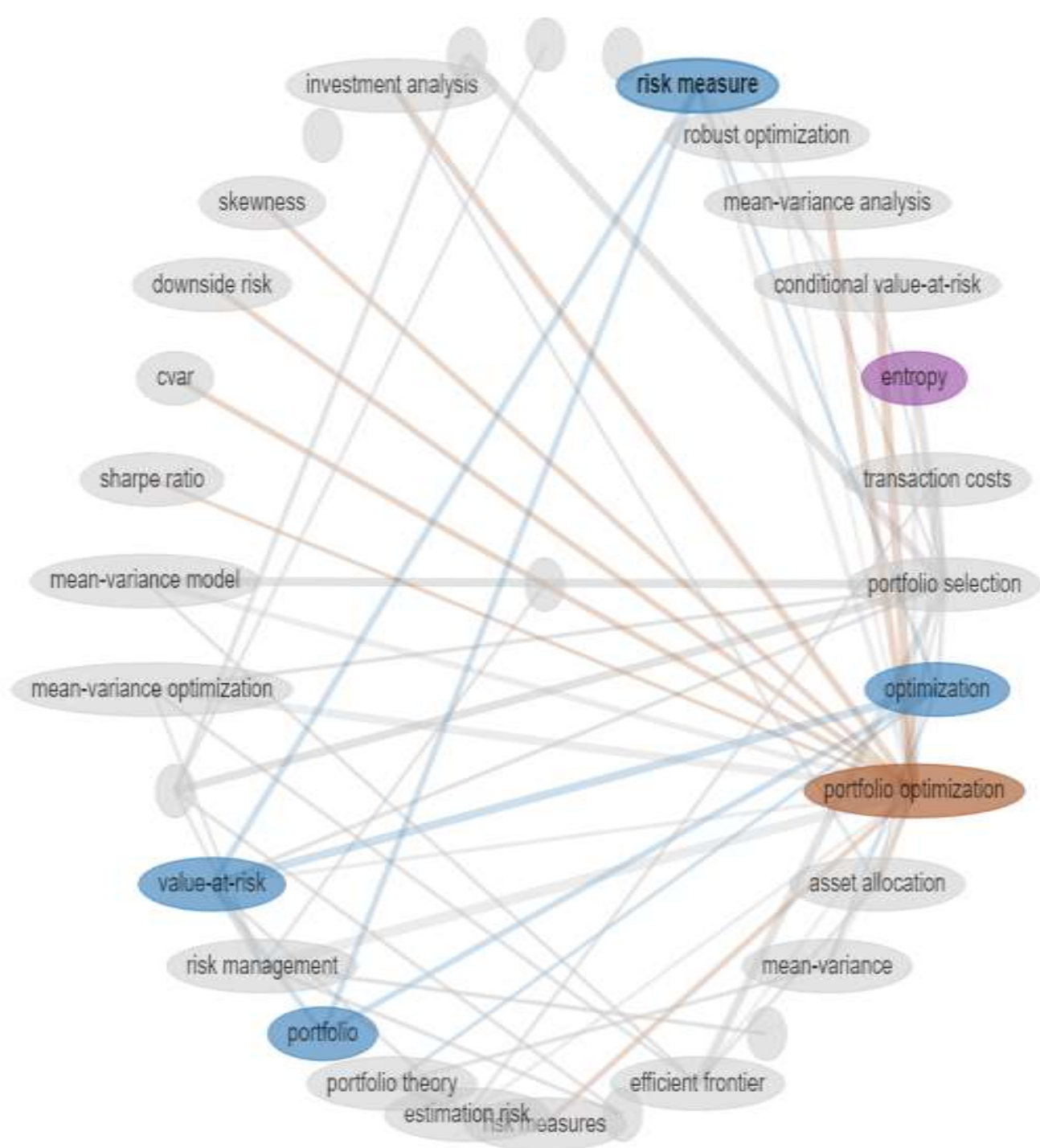

Fonte: Dados da Scopus elaborado pelo autor.

Na Figura 2 acima, as linhas em rosa identificam as keywords que tem interrelações com a keyword risk measure. As principais interrelações na pesquisa da Scopus, com co-citação filtrada pela keyword risk measure, com métricas do risco são apresentadas na Tabela 3 abaixo. 
Tabela 3: Principais co-citações filtradas pela keyword risk measure - Scopus.

\begin{tabular}{c}
\hline Principais keywords Scopus ligadas a keyword risk measure \\
\hline conditional value at risk \\
\hline conditional value-at-risk \\
\hline cvar \\
\hline downside risk \\
\hline economic and social effects \\
\hline entropy \\
\hline mean-variance \\
\hline mean-variance analysis \\
\hline mean-variance model \\
\hline mean-variance optimization \\
robust optimization \\
sharpe ratio \\
\hline skewness \\
value-at-risk \\
\hline variance
\end{tabular}

Fonte: Dados da Scopus elaborado pelo autor.

Na Figura 2 acima e na Tabela 3 acima não aparecem keywords relacionadas especificamente com a evolução do modelo de Markowizt, H., M. (1952) para métricas assimétricas do risco com resultados na forma de uma métrica assimétrica do risco com espaço objetivo aumentado e utilizando uma fórmula literal para solução do algoritmo de otimização. 
Research, Society and Development, v. 10, n. 5, e47210515189, 2021

(CC BY 4.0) | ISSN 2525-3409 | DOI: http://dx.doi.org/10.33448/rsd-v10i5.15189

A rede de co-citação pelas trinta e cinco keywords mais frequentes da pesquisa na Web of Science é apresentada abaixo na Figura 3.

Figura 3: Co-occurrence network das keywords da pesquisa na Web of Science.

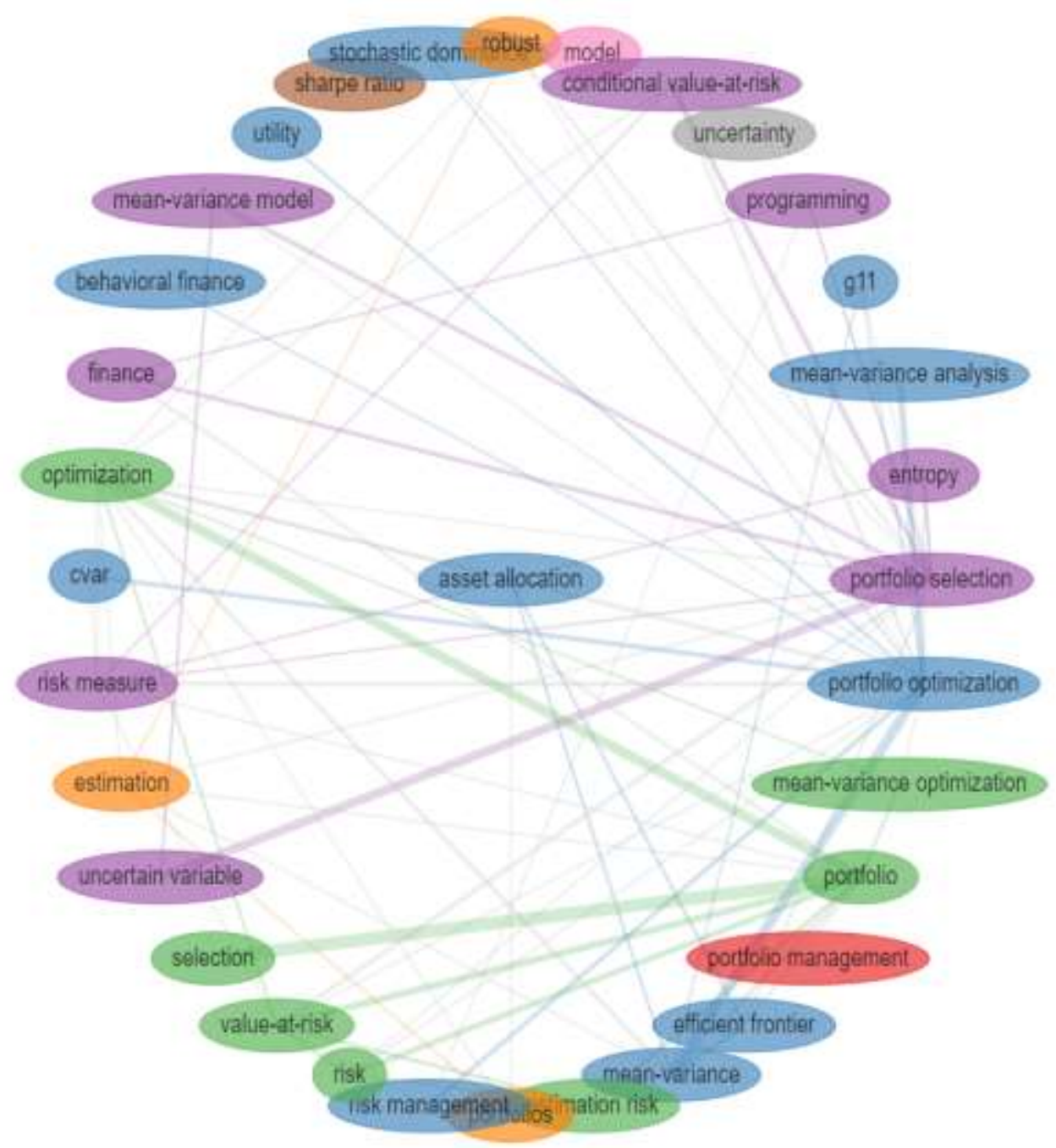

Fonte: Dados da Web of Science elaborado pelo autor.

Na Figura 3 acima, para uma melhor visualização da rede de co-citação em relação à métricas do risco, foi aplicado um filtro para a keyword risk measure. Com a aplicação do filtro se pode verificar quais são as interrelações da keyword risk measure com as demais keywords, conforme a Figura 4 a seguir. 
Research, Society and Development, v. 10, n. 5, e47210515189, 2021

(CC BY 4.0) | ISSN 2525-3409 | DOI: http://dx.doi.org/10.33448/rsd-v10i5.15189

Figura 4: Co-occurrence network da pesquisa na Web of Science com filtro para risk measure.

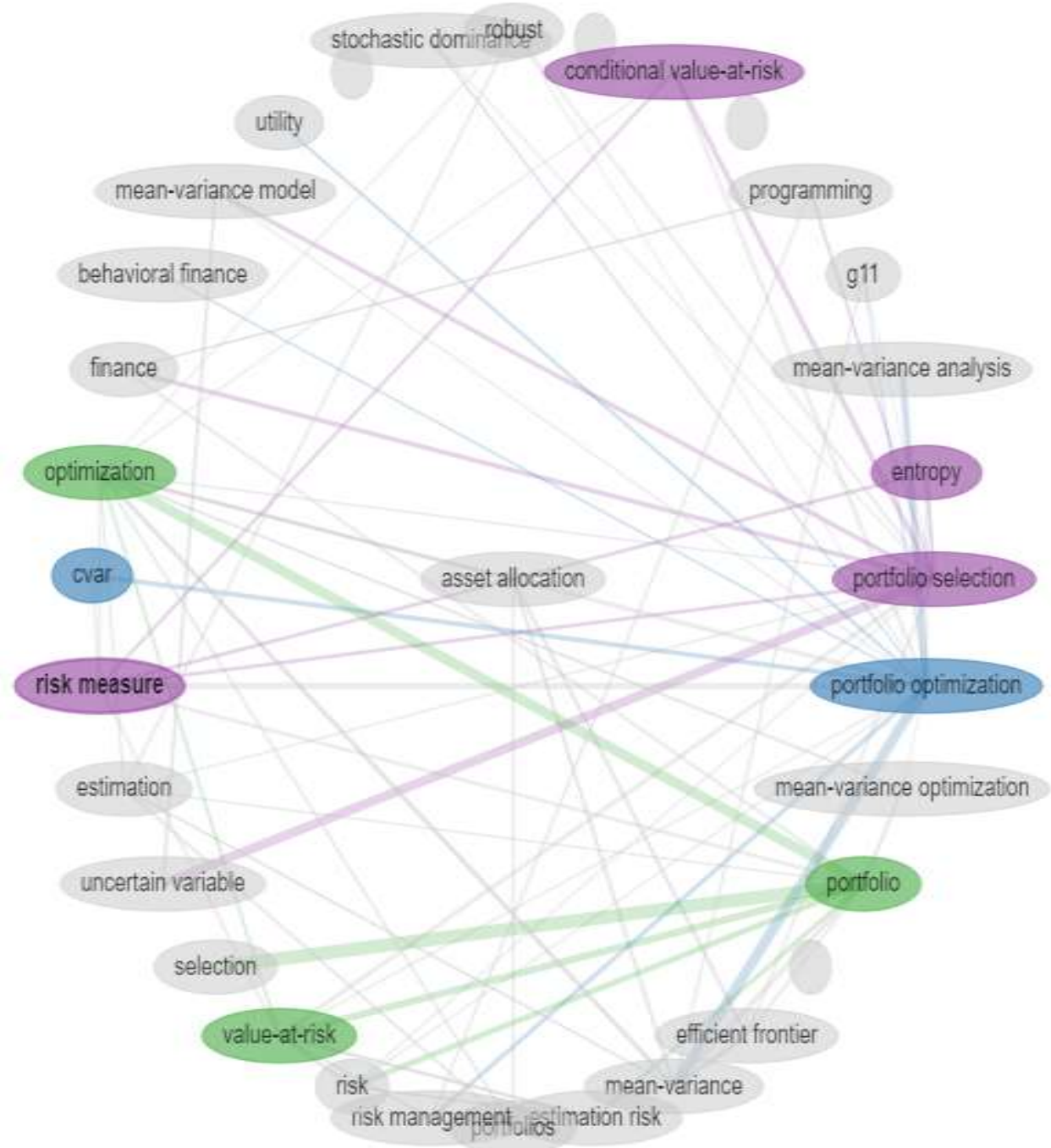

Fonte: Dados da Web of Science elaborado pelo autor.

Na Figura 4 acima, as linhas em rosa identificam as keywords que tem interrelações com a keyword risk measure. As principais interrelações na pesquisa da Web of Science, com co-citação filtrada pela keyword risk measure, com métricas do risco são apresentadas na Tabela 4 abaixo. 
Tabela 4: Principais co-citações filtradas pela keyword risk measure - Web of Science.

\begin{tabular}{c}
\hline Principais keywords Web of Science ligadas a keyword risk measure \\
\hline conditional value at risk \\
\hline conditional value-at-risk \\
\hline cvar \\
\hline downside risk \\
\hline economic and social effects \\
\hline entropy \\
\hline mean-variance \\
\hline mean-variance analysis \\
\hline
\end{tabular}

Fonte: Dados da Web of Science elaborado pelo autor.

Na Figura 4 acima e na Tabela 4 acima não aparecem keywords relacionadas especificamente com a evolução do modelo de Markowizt, H., M. (1952) para métricas assimétricas do risco com resultados na forma de uma métrica assimétrica do risco com espaço objetivo aumentado e utilizando uma fórmula literal para solução do algoritmo de otimização.

Realizando, como última etapa da bibliometria, o filtro das pesquisas em conjunto, na Scopus e na Web of Science, para separar por cluster de títulos específicos os documentos das bases de dados filtrados nos campos de keyword, keyword plus, abstract e title, pelas palavras chaves assessment, metrics, measures e estimation, se pretende verificar se existe algum artigo nas duas bases de dados que apresentem seus resultados a respeito de métrica do risco na forma de uma métrica assimétrica do risco com espaço objetivo aumentado e utilizando uma fórmula literal para solução do algoritmo de otimização, de forma a considerar um maior número de parâmetros a serem otimizados, e caso existam como são suas formulações. As bases de dados serão analisadas, com a exclusão de títulos repetidos na mesma base ou em bases diferentes, e os títulos resultantes da análise serão classificados qualitativamente em clusters e apresentados em uma tabela. Na pesquisa em conjunto, na Scopus e na Web of Science, após a aplicação dos filtros nos campos de keyword, keyword plus, abstract e title, e exclusão dos títulos repetidos, foram selecionados seiscentos e dez títulos filtrados pelas palavras chaves assessment, metrics, measures e estimation, para serem classificados em clusters. A Tabela 5 a seguir apresenta o resultado do cluster de títulos para métodos específicos a respeito de métricas do risco. 
Tabela 5: Cluster de títulos a respeito de métricas do risco.

\begin{tabular}{|c|c|}
\hline Cluster de métricas do risco & Número artigos \\
\hline \multicolumn{2}{|c|}{ Métricas do Risco } \\
\hline Variance & 193 \\
\hline Sharpe ratio & 1 \\
\hline Downside models & 7 \\
\hline Value-at-risk & 7 \\
\hline Conditional value-at-risk & 9 \\
\hline Tail dependence & 1 \\
\hline \multicolumn{2}{|c|}{ Evoluções do Modelo EV } \\
\hline Bayes & 7 \\
\hline Shrinkage & 4 \\
\hline Bootstrap & 5 \\
\hline Data envelopment analysis & 2 \\
\hline Robust optimization & 37 \\
\hline Interval selection & 1 \\
\hline Adaptive models & 2 \\
\hline Vast Portfólio & 2 \\
\hline \multicolumn{2}{|c|}{ Outros } \\
\hline Black-Litterman & 11 \\
\hline Cluster models & 3 \\
\hline Copula models & 7 \\
\hline Diversification & 29 \\
\hline Dynamic optimization & 13 \\
\hline Forecast & 9 \\
\hline Foreign studies & 4 \\
\hline Fuzzy models & 31 \\
\hline Garch models & 2 \\
\hline Genetic Algorithm & 2 \\
\hline Geometric Brownian & 1 \\
\hline Learning models & 7 \\
\hline Linear models & 11 \\
\hline Mean models & 37 \\
\hline Multi-objetive & 9 \\
\hline Multi-period models & 7 \\
\hline Multicriteria models & 1 \\
\hline Multivariate models & 5 \\
\hline Nonparametric & 5 \\
\hline Performance measures & 1 \\
\hline Stochastic models & 11 \\
\hline Diversos & 126 \\
\hline Soma & 610 \\
\hline
\end{tabular}

Fonte: Dados da Scopus e da Web of Science elaborada pelo autor.

$\mathrm{Na}$ Tabela 5 se pode ressaltar o Conditional value-at-risk com 9 ocorrências e a Robust optimization com 37 ocorrências, como respectivamente métrica do risco e evolução do modelo EV de Markowitz, H., M., (1952). 
Em função da impossibilidade de listar o grande número de artigos relacionados na Tabela 5 serão listados a seguir, para cada cluster da tabela, somente uma referência de cada cluster, sendo priorizada a referência mais relevante e/ou mais atual do cluster identificado. A totalidade das referências pode ser obtida pela realização das pesquisas na Scopus e na Web of Science, com a chave de pesquisa e as keywords utilizadas na geração da tabela.

Assim na Tabela 5, as referências são:

- $\quad$ Adaptive models: Ruidi S. \& Yue C. (2020).

- Bayes: Becker, F., Gurtler, M. \& Hibbelin M. (2015).

- $\quad$ Black-Litterman: Xinxin, J. \& Jianjun, G. (2016).

- Bootstrap: Begoña F. (2016).

- Cluster models: Mahdi, M., Masoud, M. \& Alireza A., K., (2020).

- Conditional value-at-risk: Christopher W. \& Millery I. Y. (2017).

- Copula models: Kwong, R. \& Low, Y. (2015).

- Data envelopment analysis: Edirisinghe, N.C.P.\& Zhang, X. (2010).

- Diversification: DeMiguel, V., Garlappi, L. \& Uppal, R., (2009).

- Diversos: Kolm, P. N., Tütüncü, R. \& Fabozzi, F. J. (2014).

- Downside models: Fortin, J. \& Hlouskova, J. (2015).

- Dynamic optimization: Bianchi, D. \& Guidoliny, M. (2013).

- Forecast: Allen, D., Lizieri, C. \& Satchell, S. (2019).

- Foreign studies: Owen W., S. (2015).

- Fuzzy models: Kaczmarek, K., Dymova, L. \& Sevastjanov, P. (2020).

- Garch models: Aziz, N. S. A., Spyridon V., S. \& Hasim, H. M. (2019).

- Genetic Algorithm: Lin, P. (2012).

- Geometric Brownian: Abensur, E.O., Moreira, D.F. \& Faria A.C.R. (2020).

- Interval selection: Li, X. \& Qin, Z. (2014).

- Learning models: Ban, G., Karoui, N. E. \& Lim, A. E. B. (2016).

- Linear programming: Yu, J., Chiou, W. P. \& Mu, D. (2015).

- Mean models: Banihashemi, S., Azarpour, A. M. \& Navvabpour, H. (2016).

- Multicriteria models: Santamaría, R., Aguarón, J. \& Moreno-Jiménez, J. M. (2020).

- Multiobjective models: Hilario-Caballero, A., Garcia-Bernabeu A, Salcedo, J., V. \& Vercher, M. (2020).

- Multi period models: Liu, Y., Zhang, W. \& Zhang, P. (2013).

- Multivariate models: Bianchi, M. L. \& Tassinari, G. L. (2018).

- Nonparametric: Salah, H., B., Chaouch, M., Gannoun, A., Peretti, C. \& Trabelsi, A. (2018).

- Performance measures: Caporin, M. (2014).

- Robust optimization: Tang, L. \& Ling, A. (2014). 
- Sharpe ratio: Wang, C. D., Chen Z., Lian Y. \& Chen. M. (2020).

- Shrinkage: DeMiguel, V., Martin-Utrera, A. \& Nogales, F. J. (2013).

- Stochastic models: Post, T., Karabati, S. \& Arvanitis, S. (2018).

- $\quad$ Tail dependence: Leal, R. P. C. \& Mendes, B. V. M. (2013).

- Value-at-risk: Du, Z. \& Pei, P. (2020).

- Variance: Sui, Y., Hu, J. \& Ma, F. (2020).

- Vast Portfólio: Fan, J., Zhang, J. \& Yu K. (2012).

A Tabela 5 acima apresenta os clusters dos resultados da pesquisa na Scopus e da pesquisa na Web of Science, utilizando filtros nos campos de keyword, keyword plus, abstract e title, com exclusão dos títulos repetidos, e com o objetivo de poder concluir se existem artigos que apresentem resultados a respeito de métrica do risco na forma de uma métrica assimétrica do risco com espaço objetivo aumentado e utilizando uma fórmula literal para solução do algoritmo de otimização, de forma a considerar um maior número de parâmetros a serem otimizados, e caso existam como são suas formulações.

Analisando a Tabela 2 das cinquenta mais frequentes keywords, assim como o resultado das duzentas mais frequentes keywords, como também as Tabela 3 e Tabela 4, das co-ocorrências mais frequentes, e a Tabela 5 dos clusters de títulos a respeito de métricas do risco, todos acima, a conclusão da análise bibliométrica é que os artigos revisados na pesquisa bibliométrica não apresentam um resultado para métrica do risco na forma de uma métrica assimétrica do risco com espaço objetivo aumentado e utilizando uma fórmula literal para solução do algoritmo de otimização que é a contribuição original e relevante deste artigo e que não foi identificada em nenhum dos documentos revisados na pesquisa bibliométrica realizada.

\section{Metodologia}

O presente trabalho segundo Gil, A. C. (2008) pode ser considerado como:

- $\quad$ Descritivo - ao pesquisar e descrever a evolução de um determinado método;

- Dedutivo - pois parte de princípios reconhecidos como verdadeiros e indiscutíveis, chegando a conclusões de maneira lógica, considerando que as premissas obtidas para o seu desenvolvimento são generalizadas;

- $\quad$ Aplicado - pois objetiva aplicação prática dos conhecimentos gerais a situações específicas;

- $\quad$ Pesquisa quantitativa - pois requer o uso de recursos computacionais e de técnicas estatísticas para seleção automática de dados e informações;

- $\quad$ Pesquisa qualitativa - pois também recorre a seleção e classificação sem a utilização de técnicas quantitativas;

- Pesquisa exploratória - de acordo com seus objetivos, tendo como preocupação central identificar os fatores que determinam ou que contribuem para a ocorrência dos fenômenos analisados;

e utiliza a coleta de dados secundários a partir dos repositórios de dados da Economática, da Thompson-Reuters, da Scopus e da Web of Science.

A metodologia, conforme GIL, A. C. (2008), será classificado segundo seis etapas:

- $\quad$ Etapa 1 - Definição do objetivo da pesquisa;

- $\quad$ Etapa 2 - Estudo do modelo matemático;

- $\quad$ Etapa 3 - Uso de um referencial teórico;

- $\quad$ Etapa 4 - Coleta e depuração de dados;

- $\quad$ Etapa 5 - Execução e análise dos modelos;

- $\quad$ Etapa 6 - Apresentação e análise dos resultados. 
As etapas são descritas a seguir e quando houver necessidade serão detalhadas, nas próximas Sub Seções, de forma a possibilitar uma completa compreensão do trabalho realizado.

\section{Etapa 1 - Definição do objetivo da pesquisa:}

O objetivo e a principal contribuição original e relevante do artigo é o desenvolvimento e extensão do modelo EV de otimização de portfólio proposto por Markowitz, H. M. (1952, 1956, 1959, 1976, 1987, 1991) para apresentar uma nova métrica assimétrica do risco, denominada de métrica estatística eficiente (EE) conforme apresentado na Seção 4.

- com espaço objetivo aumentado, considerando $2 n^{2}-2 n+2$ interrelações para um alvo $\mathbf{t}$, sendo $\mathbf{n}$ o número de ativos;

- possibilitando a busca por melhores resultados;

- com melhores propriedades que as métricas assimétricas do risco já desenvolvidas, e

comparar a performance dos resultados de modelos utilizando a métrica do risco do modelo $\mathbf{E V}$ com os modelos utilizando a nova métrica assimétrica do risco apresentada na Seção 4.

Para permitir uma melhor comparação entre os modelos também serão apresentadas na Seção 5, como uma segunda contribuição original e relevante do artigo, as Novas Métricas para Eficiência do Risco.

\section{Etapa 2: Estudo do modelo matemático:}

Os modelos utilizados para alcançar os objetivos propostos na Etapa 1 são o modelo de otimização de portfólios EV eficiente de Markowitz, H., M. (1952), apresentado na introdução, e o modelo de otimização de portfólios com a utilização da nova métrica assimétrica do risco que será apresentada na Seção 4.

\section{Etapa 3: Uso de um referencial teórico:}

O trabalho utiliza modelos de otimização conforme os algoritmos apresentados na Seção 3.5. Também apresenta de forma sucinta a seleção de ativos de investimentos para composição de um portfólio de ativos selecionado pelos procedimentos habituais de um investidor Brito, N. R. O. (2006), Scherer, B. (2002, 2010), detalhada na Seção 3.1. A revisão bibliométrica foi realizada na Seção 2 .

\section{Etapa 4: Coleta e depuração de dados:}

As bases de dados foram fornecidas, por meio de convênio com a PUC, pela Economática e pela Thompson-Reuters (foi necessária uma segunda fonte de dados, para o segundo período de análise, em função da PUC-Rio ter terminado o convênio com a Economática), para construção, otimização e análise dos modelos e pela Scopus e pela Web of Science para a análise bibliométrica, além de pesquisas na internet para obtenção dos dados necessários. As variáveis de entrada do estudo são retornos diários de fechamento de ações da bolsa de valores do Brasil, $[\mathrm{B}]^{3}$ (Brasil, Bolsa, Balcão), volumes de ações negociadas na $[\mathrm{B}]^{3}$, a composição do índice Ibovespa ( importante indicador do desempenho médio das cotações das ações negociadas na $[\mathrm{B}]^{3}$ formado pelas ações com maior volume negociado), histórico da taxa Selic (taxa média ajustada dos financiamentos diários apurados no Sistema Especial de Liquidação e de Custódia para títulos federais) e dados sobre a média anual do investimento considerado sem risco pelo mercado. 


\section{Etapa 5: Execução e análise dos modelos:}

Os cálculos estatísticos necessários para o trabalho foram realizados pelo software R, pelo software Statistica e pelos solvers do software de otimização da Frontline. Os modelos foram calculados, analisados e comparados utilizando um computador com dois processadores Intel® Xeon® E5-2650 v2 com 64 Gb de memória.

\section{Etapa 6: Apresentação e análise dos resultados:}

Os resultados, tabelas e figuras, do trabalho foram realizadas pelo autor, segundo as referências indicadas, utilizando diversos softwares, incluindo o R, o Excel, o Statistica e softwares de design, e são apresentadas ao longo do texto e principalmente na Seção 6, onde são detalhados os resultados obtidos.

Nas seções a seguir serão detalhados a seleção dos ativos utilizados neste trabalho, o tratamento realizado nos dados coletados, o período de realização das análises, a forma como será feita a comparação entre os dois modelos considerados, os algoritmos de otimização utilizados, os valores de entrada e de saída das análises e a forma de comparação entre os resultados dos modelos.

\subsection{Seleção dos ativos}

Dos ativos negociados na $[\mathrm{B}]^{3}$ foram selecionados ativos, conforme procedimentos usuais no mercado de capitais do Brasil, para selecionar um grupo de ativos que irão compor um portfólio de investimentos, ou seja, terão definidos os percentuais a investir em cada ativo, de forma a minimizar o risco e maximizar o retorno do investimento realizado. Os procedimentos usuais no mercado de capitais consideram:

- Os dados de retorno das ações são tratados por eventos e benefícios;

- Utilizar ações com participação anual em volume de negociação na $[\mathrm{B}]^{3}$ maior que $1 \%$; de forma que os ativos tenham representatividade em negociação na $[\mathrm{B}]^{3}$.

- Considerar um grupo de ativos que totalizem pelo menos de $25 \%$ do Ibovespa. O Ibovespa é formado por ações com maior volume de negociação na $[\mathrm{B}]^{3}$;

- Substituir as ações ON (ordinárias ao portador) por ações PN (preferenciais ao portador) quando estas estiverem também disponíveis. São ações com maior liquidez;

- Utilizar restrições em relação à volatilidade (desvio padrão) ou risco dos ativos selecionados. Os ativos considerados com alta volatilidade terão uma participação no portfólio não superior à $25 \%$, e os ativos considerados com baixa volatilidade terão uma participação no portfólio não superior à $35 \%$, de forma a aumentar a diversificação e diminuir o risco do portfólio de investimentos;

- Serão selecionados ativos que já estejam em negociação e que tenham representatividade durante todo o período de análise.

Desta forma foram selecionados dez ativos para compor o portfólio de investimento conforme listado a seguir:

- ABV3, BBDC4, BRKM5, CMIG4, GGBR4, ITSA4, PETR4, CSNA3, USIM5 e VALE3;

e que totalizam em torno de 30\% do Ibovespa em cada um dos dois períodos considerados para análise. 


\subsection{Tratamento dos dados}

As séries dos ativos foram transformadas em índice, sendo a base 100 o início do período de cada série, de forma a facilitar o manuseio dos dados. Por não serem estacionárias as séries em índice, na análise ex-post, devem ser tornadas estacionárias por diferenças finitas de primeira ordem.

\subsection{Dados e período de realização das análises}

Foram considerados dois períodos distintos para a realização das análises. Cada período considera 100 retornos diários de fechamento, utilizados para a análise ex-post, onde são calculados os modelos de otimização, e 395 consecutivos retornos diários de fechamento, utilizados para a análise ex-ante, onde os resultados dos modelos de otimização calculados na análise expost são aplicados aos 395 valores de holdout. Realizando a análise ex-ante, se obtém a eficiência do retorno dos modelos ao final do período de holdout, conforme as novas métricas para eficiência do portfólio apresentadas na Seção 5. Para cálculo dos modelos de otimização os 100 primeiros retornos diários são feitos estacionários, por diferença finita de primeira ordem, eliminando a tendência dos dados no período em que são utilizados para a análise ex-post.

Os períodos considerados são:

- $\quad$ De 04 de janeiro de 2016 a 28 de dezembro de 2017, sendo:

$\checkmark$ De 04 de janeiro de 2016 a 30 de maio de 2016, para análise ex-post;

$\checkmark$ De 31 de maio de 2016 a 28 de dezembro de 2017, para análise ex-ante.

- De 02 de janeiro de 2018 a 3 de janeiro de 2020, sendo;

$\checkmark$ De 02 de janeiro de 2018 a 28 de maio de 2018, para análise ex-post;

$\checkmark \quad$ De 29 de maio de 2018 a 3 de janeiro de 2020, para análise ex-ante.

Com o advento da pandemia de Covid-19 o segundo período de holdout foi estendido até 16 de setembro de 2020, de forma que a análise também possa ser realizada incluindo um evento extremo de stress na negociação de ativos da $[\mathrm{B}]^{3}$.

A comparação dos gráficos do Ibovespa dos dois períodos considerados e caracterização dos dois períodos pode ser feita por meio do Gráfico 1 abaixo, que apresenta a comparação da série do Ibovespa nos dois períodos considerados. A Tabela 6 a seguir apresenta os coeficientes de variação e o desvio padrão (volatilidade) dos ativos selecionados, conforme a Seção 3.1, feitos estacionários, por diferença finita de primeira ordem, para todos os retornos diários de fechamento, nos dois períodos considerados para análise e também os coeficientes de variação e os desvios padrão (volatilidade) das séries dos ativos selecionados, conforme a Seção 3.1, feitos estacionárias, por diferença finita de primeira ordem, para os primeiros 100 retornos diários de fechamento de cada período, utilizados na análise ex-post para cálculo dos modelos de otimização.

Gráfico 1: Comparação entre as séries do Ibovespa.

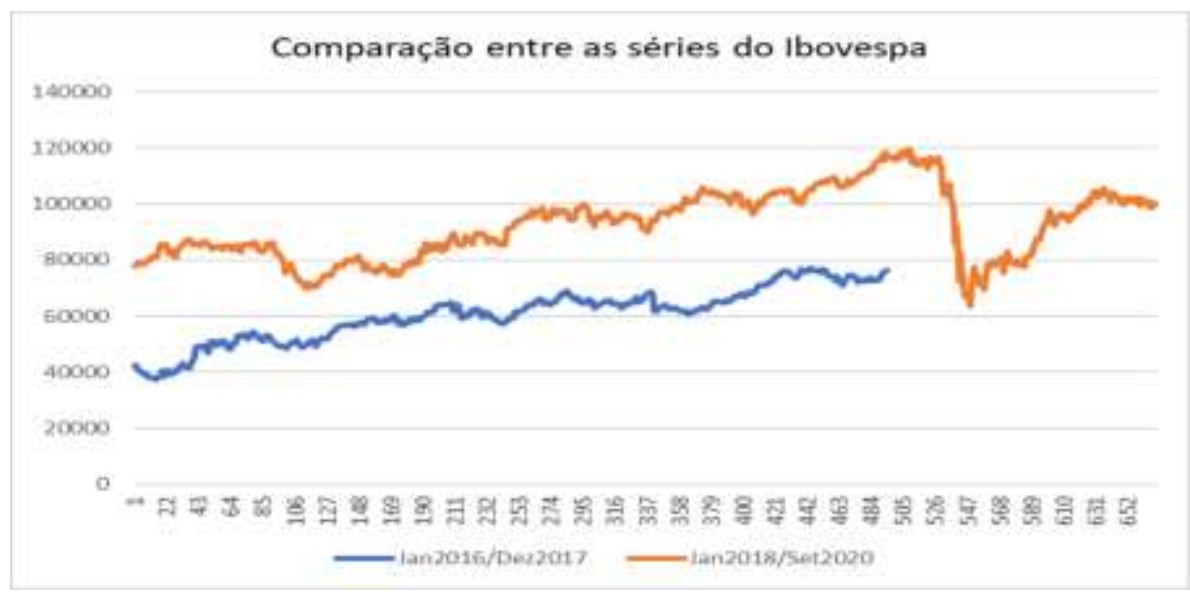

Fonte: Dados da Economática e da Thompson-Reuters elaborado pelo autor. 
Tabela 6: Coeficiente de variação e desvios padrões.

\begin{tabular}{|c|c|c|c|c|c|c|c|c|c|c|}
\hline \multicolumn{11}{|c|}{ Coeficiente de variação - séries completas (sem pandemia) } \\
\hline Período & ABEV3 & BBDC4 & BRKM5 & CMIG4 & GGBR4 & ITSA4 & PETR4 & CSNA3 & USIM5 & VALE3 \\
\hline Jan2016/Dez2017 & $4.63 \%$ & $7.30 \%$ & $5.89 \%$ & $0.18 \%$ & $5.62 \%$ & $7.50 \%$ & $4.66 \%$ & $2.19 \%$ & $7.61 \%$ & $7.06 \%$ \\
\hline $\operatorname{Jan} 2018 / \operatorname{Jan} 2020$ & $-1.24 \%$ & $4.05 \%$ & $-2.20 \%$ & $5.86 \%$ & $3.54 \%$ & $5.53 \%$ & $4.21 \%$ & $3.66 \%$ & $-0.20 \%$ & $2.87 \%$ \\
\hline \multicolumn{11}{|c|}{ Desvio padrão - séries completas (sem pandemia) } \\
\hline Período & ABEV3 & BBDC4 & BRKM5 & CMIG4 & GGBR4 & ITSA4 & PETR4 & CSNA3 & USIM5 & VALE3 \\
\hline Jan2016/Dez2017 & 1.24 & 2.96 & 3.51 & 4.86 & 5.75 & 2.41 & 4.69 & 7.89 & 11.47 & 5.49 \\
\hline Jan2018/Jan2020 & 1.46 & 2.36 & 2.31 & 3.32 & 2.50 & 2.12 & 3.30 & 4.70 & 2.95 & 2.46 \\
\hline \multicolumn{11}{|c|}{ Coeficiente de variação - análise ex-post } \\
\hline Período & ABEV3 & BBDC4 & BRKM5 & CMIG4 & GGBR4 & ITSA4 & PETR4 & CSNA3 & USIM5 & VALE3 \\
\hline Jan2016/Maio2016 & $7.55 \%$ & $10.11 \%$ & $6.80 \%$ & $0.15 \%$ & $3.44 \%$ & $7.84 \%$ & $4.34 \%$ & $4.83 \%$ & $1.93 \%$ & $2.02 \%$ \\
\hline Jan2018/Maio2018 & $7.50 \%$ & $3.63 \%$ & $3.90 \%$ & $4.23 \%$ & $4.50 \%$ & $3.73 \%$ & $0.57 \%$ & $4.53 \%$ & $3.99 \%$ & $11.97 \%$ \\
\hline \multicolumn{11}{|c|}{ Desvio padrão -análise expost } \\
\hline Período & ABEV3 & BBDC4 & BRKM5 & CMIG4 & GGBR4 & ITSA4 & PETR4 & CSNA3 & USIM5 & VALE3 \\
\hline Jan2016/Maio2016 & 1.61 & 3.95 & 2.70 & 5.58 & 6.86 & 3.18 & 5.12 & 14.26 & 8.17 & 6.27 \\
\hline Jan2018/Maio2018 & 1.16 & 1.91 & 2.31 & 2.69 & 3.45 & 2.30 & 4.17 & 3.42 & 3.21 & 2.01 \\
\hline
\end{tabular}

Fonte: Dados da Economática e da Thompson-Reuters elaborado pelo autor.

Dos Gráfico 1 e Tabela 6 acima pode ser feita a comparação e caracterização dos dois períodos de dados utilizados, o primeiro de 04 de janeiro de 2016 a 28 de dezembro de 2017 e o segundo de 02 de janeiro de 2018 a 3 de janeiro de 2020 , sem considerar a pandemia:

- As duas séries do Ibovespa apresentam uma leve tendência de alta, lenta recuperação do mercado (sem considerar o advento da pandemia de Covid-19 na segunda série);

- As duas séries do Ibovespa apresentam, diversos pontos de stress, queda e recuperação do mercado (sem considerar o advento da pandemia de Covid-19 na segunda série).

- Quando feitas estacionárias, por diferença finita de primeira ordem, as séries dos ativos selecionados, conforme a Seção 3.1, apresentam, para o primeiro período considerado acima, sem considerar a pandemia, oito dos dez ativos selecionados com maiores coeficientes de variação, o que pode permitir uma melhor performance dos resultados dos modelos de otimização nas análises ex-ante realizadas a partir do primeiro período de holdout.

- Quando feitas estacionárias, por diferença finita de primeira ordem, as séries dos ativos selecionados, conforme a Seção 3.1, apresentam, para o primeiro período considerado acima, sem considerar a pandemia, nove dos dez ativos selecionados com maiores volatilidades, o que também pode permitir uma melhor performance dos resultados dos modelos de otimização nas análises ex-ante realizadas a partir do primeiro período de holdout.

A Tabela 6 acima também apresenta os coeficientes de variação e os desvios padrão (volatilidade) das séries dos ativos selecionados, conforme a Seção 3.1, feitos estacionárias, por diferença finita de primeira ordem, para os primeiros 100 retornos diários de fechamento, de cada período, utilizados na análise ex-post para cálculo dos modelos de otimização. No período da análise ex-post a primeira série apresenta seis dos dez ativos, selecionados conforme a Seção 3.1, com maior coeficiente de variação e todos os dez ativos com maior desvio padrão o que pode permitir uma melhor performance dos resultados dos modelos na análise ex-post do primeiro período considerado.

\subsection{Comparação entre os modelos}

Nesta seção serão analisados a taxa Selic, o ativo considerado sem risco e o ponto de comparação, mínimo retorno requerido (MRR), para utilização na Seção 6 de resultados da comparação dos modelos.

A taxa média anual da Selic em 2016 foi de 14,1\% a.a. e em 2018 foi de 6,5\% a.a. O ativo considerado sem risco pode 
ser considerado como $8 \%$ a.a. em 2016 e como $4 \%$ a.a. em 2018. O que nos fornece para os períodos de 100 retornos diários de fechamento, utilizados para as análises ex-post, um ativo livre de risco respectivamente de aproximadamente $2 \%$ de 04 de janeiro de 2016 a 30 de maio de 2016, ou seja, de $0.02 \%$ ao dia, e de aproximadamente de $1 \%$ de 02 de janeiro de 2018 a 28 de maio de 2018 , ou seja de aproximadamente $0.01 \%$ ao dia.

Para que se possa comparar a performance dos resultados dos dois modelos considerados é necessário determinar o mínimo retorno requerido (MRR) que será utilizado para a comparação entre os modelos. De forma a considerar o MRR de forma imparcial, na consideração dos resultados dos modelos, foi determinado que o ponto para comparação dos modelos será o MRR fornecido pela tangência da linha de alocação de capital (LAC) com a fronteira eficiente (FE) de Markowitz, H., M. (1952) como uma referência ao procedimento da tangência da LAC, conforme definido em Tobin, J. (1958a,b), com a FE que fornece, considerando o ativo livre de risco, o ponto ótimo onde todo os investimentos estão em ativos de risco, ou seja o portfólio de mercado. Pontos na LAC acima da tangência fornecem um portfólio alavancado por ativos de risco e pontos abaixo da tangência possuem ativos livres de risco. Neste trabalho se considera a otimização de ativos de risco, e assim se considera o conceito do ponto de tangência da LAC com a FE que é utilizado como o ponto de comparação entre os modelos.

\subsection{Algoritmos de solução}

Os algoritmos utilizados para resolver os modelos de otimização são descritos a partir do Solvers Reference Guide (2020) da Frontline Systems, especificamente o LP / Quadratic Solver para a otimização quadrática e o GRG Nonlinear Solver para a otimização não linear. Pela relevância com o tema, também foi incluída uma descrição do Evolutionary Solver para a otimização não suave.

Os algoritmos de programação linear (LP) da Frontline usam uma implementação mais sofisticada do método Simplex que explora a dispersão no modelo LP e usa técnicas como pré-resolução, fatoração de matriz usando a decomposição LU, um método LU atualizado, rápido e estável, e refatoração dinâmica de Markowitz.

Os algoritmos de programação quadrática (QP) são mais complexos do que os algoritmos $\mathbf{L P}$, mas mais simples do que os problemas gerais de otimização não suave (NSP). Eles têm apenas uma região viável com "faces planas" em sua superfície (devido às suas restrições lineares), mas a solução ótima pode ser encontrada em qualquer lugar dentro da região ou em sua superfície. O LP / Quadratic Solver resolve problemas de QP usando uma variante do método Simplex para determinar a região viável e métodos especiais baseados nas propriedades de funções quadráticas, e dos métodos de Ponto Interior e de quase Newton para encontrar a solução ideal. A maioria dos algoritmos de programação quadrática é especializada para lidar apenas com quadráticas definidas positivas (ou definidas negativas). O LP / Quadratic Solver, entretanto, também pode lidar com quadráticas semidefinidas; encontrando uma das equivalentes (globalmente) soluções ótimas - as quais dependem dos valores iniciais das variáveis de decisão. Quando aplicado a uma função objetiva quadrática indefinida, o LP / Quadratic Solver fornece apenas as garantias de um Solver não linear geral: ele convergirá para uma solução ideal local (um ponto de sela no interior ou uma solução ideal localmente na superfície de restrição).

O GRG Nonlinear Solver, para otimização não linear usa o código Generalized Reduced Gradient (GRG2), que foi desenvolvido por Leon Lasdon, da Universidade do Texas em Austin, e Alan Waren, da Cleveland State University, e aprimorado pela Frontline Systems Inc., a partir do artigo original de Lasdon, L. S., Waren, A., D., Jain, A. \& Ratner, M., W. (1975). Design and testing of a generalized reduced gradient code for nonlinear optimization, Case Western Reserve University, prepared for: Office of Naval Research - 1975. Utiliza ainda o método multistart que opera gerando pontos de partida candidatos para o solver não linear (com valores selecionados aleatoriamente entre os limites especificados para as variáveis). Esses pontos são então agrupados em "clusters" por meio de um método denominado ligação única de vários níveis. O Solver não linear é então executado repetidamente, uma vez de cada cluster. O processo continua com clusters sucessivamente menores que têm cada vez 
mais probabilidade de capturar cada solução ideal localmente possível. Um teste Bayesiano é usado para determinar se o processo deve continuar ou parar. Para muitos problemas não lineares suaves, o método multistart tem uma garantia limitada de que "convergirá em probabilidade" para uma solução globalmente ótima. Isso significa que, conforme o número de execuções do solver não linear aumenta, a probabilidade de que a solução globalmente ótima tenha sido encontrada também aumenta para $100 \%$.

O Evolutionary Solver para otimização não suave usa uma variedade de algoritmos genéticos e métodos de busca local, implementados por vários indivíduos na Frontline Systems Inc. O Evolutionary Solver opera combinando as estratégias usadas por um algoritmo evolutivo com os métodos de otimização “clássicos” usados pelo GRG não linear e pelo LP / Quadratic Solver, mas também emprega métodos clássicos em duas situações: primeiro, quando o algoritmo evolucionário gera um novo melhor ponto, uma busca local é conduzida para tentar melhorar esse ponto. Esta etapa pode usar um método de "pesquisa local aleatória", um método de pesquisa direta determinística sem gradiente, um método quase Newton baseado em gradiente ou um método de "gradiente local linearizado". Em segundo lugar, quando o algoritmo evolucionário gera um ponto inviável, o Solver pode usar "métodos de reparo", um método quase Newton ou mesmo um método simplex especializado (para subconjuntos de restrições que são lineares) para transformar o ponto inviável em um viável.

\subsection{Valores de entrada dos modelos, comparação entre os modelos e resultados dos modelos}

Na Seção 6 são apresentadas a comparação da performance dos resultados dos modelos de otimização de portfólio EV eficiente de Markowitz, H., M. (1952) (EV) com os modelos de otimização de portfólio utilizando a nova métrica do risco estatística eficiente (EE), apresentada na Seção 4.

Na comparação da performance dos resultados são consideradas como entrada de dados de cada modelagem, de forma independente, os valores de fechamento do retorno diário dos ativos selecionados, conforme a Seção 3.1, conforme cada um dos dois períodos de séries de dados apresentadas na Seção 3.3. Os 100 primeiros valores de cada uma das séries são feitos estacionários, por diferença finita de primeira ordem, e são utilizados, conforme a Seção 3.4, para o cálculo das frações ótimas a investir em cada ativo, do risco ótimo, do retorno ótimo e, somente para o modelo $\mathbf{E V}$, da fronteira eficiente (FE) considerando todos os mínimos retorno requeridos especificados, pela realização de análises ex-post. Em cada uma das séries, os sequenciais valores de holdout são utilizados para comparar a eficiência do retorno ao final do período de holdout e a prevalência dos modelos ao longo do período de holdout, conforme as novas métricas para eficiência do portfólio apresentadas na Seção 5, pela realização de análises ex-ante.

Conforme a Seção 3.3, os períodos de séries de dados considerados na Seção 6 são:

- De 04 de janeiro de 2016 a 28 de dezembro de 2017, sendo;

$\checkmark$ De 04 de janeiro de 2016 a 30 de maio de 2016, para análise ex-post;

$\checkmark$ De 31 de maio de 2016 a 28 de dezembro de 2017, para análise ex-ante.

- De 02 de janeiro de 2018 a 16 de setembro de 2020, sendo;

$\checkmark$ De 02 de janeiro de 2018 a 28 de maio de 2018, para análise ex-post;

$\checkmark$ De 29 de maio de 2018 a 16 de setembro de 2020, para análise ex-ante.

Na Seção 6 são apresentadas a comparação, conforme as novas métricas para eficiência dos portfólios apresentadas na Seção 5, da performance dos resultados dos modelos de otimização pelo uso da métrica do risco do modelo $\mathbf{E V}$ com o modelo utilizando a nova métrica do risco estatística eficiente (EE).

As médias e as métricas do risco dos modelos de otimização $\mathbf{E V}$ e EE são calculadas, a partir dos ativos selecionados na Seção 3.1, de forma independente, no período de 04 de janeiro de 2016 a 30 de maio de 2016 e no período de 02 de janeiro de 2018 a 28 de maio de 2018, para serem utilizadas como entrada pelos modelos de otimização na realização das análises $e x$ - 
post. Em cada um dos períodos de dados, a partir das médias e das métrica do risco, os modelos de otimização com a métrica do risco EV de otimização são calculados para diferentes valores especificados de mínimo retorno requerido (MRR), construindo a fronteira eficiente $(\mathbf{F E})$ para o modelo $\mathbf{E V}$, e determinando um ponto para comparação da performance do resultado dos modelos, pela tangência da LAC com a FE conforme a Seção 3.4. Em cada um dos períodos de dados, a partir das médias e das métricas do risco, os modelos de otimização com a métrica do risco EE são calculados para o MRR definido pelo ponto determinado para a comparação da performance dos resultados dos modelos.

Para cada modelo e em cada um dos períodos de dados, são calculados os percentuais a investir em cada ativo que são utilizados com os sequenciais valores de holdout de cada série de dados para comparar a eficiência do retorno ao final de cada um dos períodos de holdout, realizando duas análises ex-ante. Também são apresentadas a prevalência entre os modelos considerando os retornos diários ao longo de cada um dos períodos de holdout. Nas análises ex-post a performance dos resultados dos modelos são comparadas pelas novas métricas para eficiência do portfólio conforme a Seção 5. As performances dos resultados dos modelos no período de holdout também serão comparadas com o Ibovespa.

\section{Métrica do Risco com Espaço Objetivo Aumentado}

Segundo Rubinstein, M. (2002), no seu artigo Markowitz's "Portfolio Selection": A Fifty-Year Retrospective, "provavelmente, o aspecto mais importante do trabalho de Markowitz foi mostrar que não é o risco do próprio título que é importante para um investidor, mas sim a contribuição que o título dá para a variação de todo o seu portfólio - e que isso era principalmente uma questão de covariância com todos os outros títulos em seu portfólio". Assim, será apresentada nesta seção, como a principal contribuição original e relevante do artigo, uma nova métrica assimétrica do risco, denominada de métrica do risco estatística eficiente (EE), com um maior detalhamento das interrelações entre os ativos, considerando vários subgrupos homogêneos entre os ativos, de forma a medir a contribuição de cada subgrupo dos ativos para o risco do portfólio.

Esta nova métrica assimétrica do risco, por apresentar um maior detalhamento das interrelações entre os ativos, apresenta um modelo de otimização com espaço objetivo aumentado, proporcionando um maior número de parâmetros a serem otimizados, ou seja, permitindo avaliar um maior número de interrelações entre os ativos, o que possibilita a busca por melhores resultados quando comparado com o modelo de portfólio $\mathbf{E V}$ e outros modelos de portfólio que consideram a assimetria pelos desvios acima e/ou abaixo de um retorno alvo $\mathbf{t}$.

Além disso, a nova métrica assimétrica do risco utiliza uma formula literal que permite a solução por um algoritmo de otimização não linear (NLP), que pode convergir para um ótimo global, com reduzido consumo computacional em relação ao algoritmo não suave, usualmente utilizado pelas métricas assimétricas do risco, que apresentam apenas uma solução viável ou um ótimo local.

É importante notar que, a nova métrica assimétrica do risco fornece uma fórmula literal para a métrica do risco do modelo de otimização em função das métricas do risco dos ativos considerados, ou seja, o problema de otimização pode ser resolvido por uma expressão literal utilizando valores empíricos da amostra para calcular a métrica do risco do modelo de otimização como uma função das métricas do risco dos $\mathbf{n}$ ativos do portfólio. Assim, a nova métrica assimétrica do risco apresenta uma formula literal que permite a solução por um algoritmo de otimização não linear (NLP), que pode convergir para um ótimo global. O algoritmo não linear utiliza reduzida capacidade de processamento para solução do modelo, mesmo com um maior número de parâmetros, em comparação ao algoritmo não suave (NSP), usualmente utilizado pelas métricas assimétricas do risco, que apresentam apenas uma solução viável ou um ótimo local.

M é definida como a matriz das integrais dos desvios quadrados e desvios quadrados cruzados dos retornos do portfólio, para o alvo t: 


$$
\mathbf{M}(\mathbf{i}, \mathbf{j})=\int_{-\infty}^{\infty} \int_{-\infty}^{\infty}\left(\mathbf{r}_{\mathbf{p i}}-\mathbf{t}\right)\left(\mathbf{r}_{\mathbf{p j}}-\mathbf{t}\right) \mathbf{f}_{\mathbf{i j}}\left(\mathbf{x}_{\mathbf{i}}, \mathbf{x}_{\mathbf{j}}\right) \mathbf{d} \mathbf{x}_{\mathbf{i}} \mathbf{d} \mathbf{x}_{\mathbf{j}}
$$

onde t é o alvo, ou o mínimo retorno aceitável, e $\boldsymbol{f}_{\boldsymbol{i} \boldsymbol{j}}$ representa a função de densidade de probabilidade conjunta dos ativos i e j. Considerando i = j em (5), se obtém:

$$
M(i, i)=\int_{-\infty}^{\infty}\left(r_{p i}-t\right)^{2} f_{i}\left(x_{i}\right) d x_{i}
$$

Proposição 1: A matriz $\mathbf{M}(\mathbf{i}, \mathbf{j})=\int_{-\infty}^{\infty} \int_{-\infty}^{\infty}\left(\mathbf{r}_{\mathbf{p i}}-\mathbf{t}\right)\left(\mathbf{r}_{\mathbf{p j}}-\mathbf{t}\right) \mathbf{f}_{\mathbf{i j}}\left(\mathbf{x}_{\mathbf{i}}, \mathbf{x}_{\mathbf{j}}\right) \mathbf{d} \mathbf{x}_{\mathbf{i}} \mathbf{d} \mathbf{x}_{\mathbf{j}}$, pode ser decomposta na soma de $2 \mathbf{n}^{2}$ 2n +2 matrizes, denotadas por $M^{+}, M^{-}$e $M^{++}, M^{+-}, M^{-+}, M^{--}$,com $1 \leq \mathrm{i} \leq \mathrm{j} \leq \mathrm{n}$, com base nos retornos $\mathbf{r}_{\mathbf{i}}$ e densidades $\boldsymbol{f}_{\boldsymbol{i}}$ dos ativos e no alvo $\mathbf{t}$, de tal modo que:

$$
\begin{aligned}
& M_{i i}^{+}(i, i)=\int_{\mathrm{x}_{\mathrm{i}}=\mathrm{t}}^{\infty}\left(r_{i}-t\right)^{2} f_{i}\left(r_{i}\right) d x_{i}, \mathrm{e} M^{+}(i, j)=0, \mathbf{i} \neq \mathbf{j} \\
& M_{i i}^{-}(i, i)=\int_{\mathrm{x}_{\mathrm{i}}=-\infty}^{t}\left(r_{i}-t\right)^{2} f_{i}\left(r_{i}\right) d x_{i}, \text { e } M^{-}(i, j)=0, \mathbf{i} \neq \mathbf{j} \\
& \boldsymbol{M}_{i j}^{++}(\boldsymbol{i}, \boldsymbol{j})=\boldsymbol{M}_{i j}^{++}(\boldsymbol{j}, \boldsymbol{i})=\int_{\mathrm{x}_{\mathrm{i}}=\boldsymbol{t}}^{\infty} \int_{\mathrm{x}_{\mathrm{i}}=\boldsymbol{t}}^{\infty}\left(\boldsymbol{r}_{\boldsymbol{i}}-\boldsymbol{t}\right)\left(\boldsymbol{r}_{\boldsymbol{j}}-\boldsymbol{t}\right) \boldsymbol{f}_{\boldsymbol{i j}}\left(\boldsymbol{r}_{\boldsymbol{i}}, \boldsymbol{r}_{\boldsymbol{j}}\right) \boldsymbol{d} \boldsymbol{x}_{\boldsymbol{i}} \boldsymbol{d} \boldsymbol{x}_{\boldsymbol{j}} \text {, e } 0 \text { para as demais entradas; } \\
& \mathbf{M}_{\mathbf{i j}}^{+-}(\mathbf{i}, \mathbf{j})=\mathbf{M}_{\mathbf{i j}}^{+-}(\mathbf{j}, \mathbf{i})=\int_{\mathbf{x}_{\mathbf{i}}=\mathbf{t}}^{\infty} \int_{\mathbf{x}_{\mathbf{j}}=-\infty}^{\mathbf{t}}\left(\mathbf{r}_{\mathbf{i}}-\mathbf{t}\right)\left(\boldsymbol{r}_{\mathbf{j}}-\mathbf{t}\right) \mathbf{f}_{\mathbf{i j}}\left(\mathbf{r}_{\mathbf{i}}, \boldsymbol{r}_{\mathbf{j}}\right) \mathbf{d} \mathbf{x}_{\mathbf{i}} \mathbf{d} \mathbf{x}_{\mathbf{j}}, \text { e } 0 \text { para as demais entradas; } \\
& \mathbf{M}_{\mathbf{i j}}^{-+}(\mathbf{i}, \mathbf{j})=\mathbf{M}_{\mathbf{i j}}^{-+}(\mathbf{j}, \mathbf{i})=\int_{\mathbf{x}_{\mathbf{i}}=-\infty \mathbf{t}}^{\mathbf{t}} \int_{\mathbf{x}_{\mathbf{j}}=\mathbf{t}}^{\infty}\left(\mathbf{r}_{\mathbf{i}}-\mathbf{t}\right)\left(\mathbf{r}_{\mathbf{j}}-\mathbf{t}\right) \mathbf{f}_{\mathbf{i j}}\left(\mathbf{r}_{\mathbf{i}}, \mathbf{r}_{\mathbf{j}}\right) \mathbf{d} \mathbf{x}_{\mathbf{i}} \mathbf{d} \mathbf{x}_{\mathbf{j}} \text {, e } 0 \text { para as demais entradas; } \\
& \mathbf{M}_{\mathbf{i j}}^{--}(\mathbf{i}, \mathbf{j})=\mathbf{M}_{\mathbf{i j}}^{--}(\mathbf{j}, \mathbf{i})=\int_{\mathbf{x}_{\mathbf{i}}=-\infty}^{\mathbf{t}} \int_{\mathbf{x}_{\mathbf{j}}=-\infty}^{\mathbf{t}}\left(\mathbf{r}_{\mathbf{i}}-\mathbf{t}\right)\left(\mathbf{r}_{\mathbf{j}}-\mathbf{t}\right) \mathbf{f}_{\mathbf{i j}}\left(\mathbf{r}_{\mathbf{i}}, \mathbf{r}_{\mathbf{j}}\right) \mathbf{d} \mathbf{x}_{\mathbf{i}} \mathbf{d} \mathbf{x}_{\mathbf{j}} \text {, e } 0 \text { para as demais entradas. }
\end{aligned}
$$

As propriedades das matrizes e de desmembramento das integrais facilmente realizam a dedução deste resultado. As fórmulas empíricas análogas as integrais acima são, para uma amostra de tamanho $\mathbf{z}$, respectivamente:

$$
\begin{aligned}
& \mathbf{M}(\mathbf{i}, \mathbf{j})=\sum_{1 \leq s \leq z}\left(\mathbf{r}_{\text {pis }}-\mathbf{t}\right)\left(\mathbf{r}_{\mathbf{p j s}}-\mathbf{t}\right) \\
& M_{i i}^{+}(i, i)=\sum_{\substack{1 \leq s \leq z, r_{i s}>t,}}\left(r_{i s}-t\right)^{2}, M^{+}(i, j)=0, \mathbf{i} \neq \mathbf{j} \\
& \mathbf{M}_{\mathrm{ii}}^{-}(\mathbf{i}, \mathbf{i})=\sum_{\substack{1 \leq \mathbf{s} \leq \mathrm{z}, \mathrm{r}_{\mathrm{is}}<\mathrm{t},}}\left(\boldsymbol{r}_{i s}-\mathbf{t}\right)^{2}, M^{-}(i, j)=\mathbf{0}, \mathbf{i} \neq \mathbf{j} \\
& \mathbf{M}_{\mathbf{i j}}^{++}(\mathbf{i}, \mathbf{j})=\mathbf{M}_{\mathbf{j i}}^{++}(\mathbf{j}, \mathbf{i})=\sum_{\substack{\mathbf{1} \leq \mathbf{s} \leq \mathbf{z}, \mathbf{r}_{\mathbf{i}} \geq \mathbf{t}, \mathbf{r}_{\mathbf{j} s} \geq \mathbf{t}}}\left(\boldsymbol{r}_{i s}-\mathbf{t}\right)\left(\mathbf{r}_{\mathbf{j s}}-\mathbf{t}\right), \text { e } 0 \text { para as outras entradas; }
\end{aligned}
$$




$$
\left.\mathbf{M}_{\mathbf{i j}}^{+-}(\mathbf{i}, \mathbf{j})=\mathbf{M}_{\mathbf{j i}}^{+-}(\mathbf{j}, \mathbf{i})=\sum_{\substack{\mathbf{1} \leq \mathbf{s} \leq \mathbf{z},\left(\mathbf{r}_{\mathbf{i s}} \\ \mathbf{r}_{\mathbf{i} s} \geq \mathbf{t}, \mathbf{r}_{\mathbf{i s}}<\mathbf{t}\right.}}-\mathbf{t}\right)\left(\mathbf{r}_{\mathbf{j s}}-\mathbf{t}\right), \text { e } 0 \text { para as outras entradas; }
$$

$$
\mathbf{M}_{\mathbf{i j}}^{-+}(\mathbf{i}, \mathbf{j})=\mathbf{M}_{\mathbf{j i}}^{-+}(\mathbf{j}, \mathbf{i})=\sum_{\substack{\mathbf{1} \leq \mathbf{s} \leq \mathbf{z}, \mathbf{r}_{\mathbf{i s}}<\mathbf{t}, \mathbf{r}_{\mathbf{j} \mathbf{s}} \geq \mathbf{t}}}\left(\boldsymbol{r}_{i s}-\mathbf{t}\right)\left(\mathbf{r}_{\mathbf{j s}}-\mathbf{t}\right) \text {, e 0 para as outras entradas; }
$$

$$
\mathbf{M}_{\mathbf{i j}}^{--}(\mathbf{i}, \mathbf{j})=\mathbf{M}_{\mathbf{j i}}^{--}(\mathbf{j}, \mathbf{i})=\sum_{\substack{\mathbf{1} \leq \mathbf{s} \leq \mathbf{z}, \mathbf{r}_{\mathbf{i s}}<\mathbf{t}, \mathbf{r}_{\mathbf{j} \mathbf{s}}<\mathbf{t}}}\left(\mathbf{r}_{\mathbf{i s}}-\mathbf{t}\right)\left(\mathbf{r}_{\mathbf{j s}}-\mathbf{t}\right) \text {, e 0 para as outras entradas. }
$$

A nova métrica do risco proposta a seguir para resolver o problema de otimização, referida como métrica do risco estatística eficiente (EE), utiliza fórmulas empíricas análogas à matriz $\mathbf{M}$ apresentada em (5) para uma amostra de tamanho $\mathbf{z}$.

A matriz $\mathbf{M}$ apresentada em (5) não só leva em consideração os desvios dos retornos acima e abaixo do alvo $\mathbf{t}$, como permite avaliar um maior número de interrelações entre os ativos, e também fornece para seu cálculo uma forma literal, que utiliza valores empíricos, com base no retorno dos ativos e do alvo t.

Como na Seção 1 em que o risco que foi calculado como $\boldsymbol{Q}=\boldsymbol{W}^{\prime} \mathbf{Q} \boldsymbol{W}$, onde $\mathbf{Q}$ é a matriz de variância-covariância dos ativos, também se pode calcular o risco pela matriz $\mathcal{M}$ definida como $\mathcal{M}=\boldsymbol{W}^{\prime} \mathbf{M} \boldsymbol{W}$, onde a métrica do risco $\mathbf{M}$ apresentada em (5), dos desvios quadrados e desvios quadrados cruzados dos retornos $\mathbf{r}_{\mathbf{p s}}$ para um alvo $\mathbf{t}$, também considera os desvios acima e abaixo do alvo $\mathbf{t}$, como os atuais modelos com métricas assimétricas do risco que geram um problema de otimização não suave (NSP). Porém, além de considerar os desvios acima e abaixo do alvo t, a matriz $\mathbf{M}$, apresentada em (5), permite avaliar um maior número de interrelações entre os ativos para o alvo $\mathbf{t}$, pelo desmembramento da matriz $\mathbf{M}$ em $2 n^{2}-2 n+2$ matrizes, o que permite que o modelo de otimização seja resolvido por meio de uma forma literal, com base nos retornos dos ativos e do alvo $\mathbf{t}$, o que transforma o algoritmo de otimização em um problema quadrático $(\mathbf{Q P})$.

Proposição 2: A matriz $\mathbf{M}$, apresentada em (5), dos desvios quadrados e desvios cruzados dos retornos $\mathbf{r}_{\mathbf{p s}}$ em relação à um mínimo retorno aceitável (MRA) t, em um portfólio de ativos $\boldsymbol{A}_{\mathbf{1}}, \boldsymbol{A}_{\mathbf{2}}, \ldots, \boldsymbol{A}_{\boldsymbol{n}}$, pode ser escrita como uma função dos desvios quadrados e desvios quadrados cruzados dos retornos $\boldsymbol{r}_{\boldsymbol{i}}$ de cada ativo $\boldsymbol{A}_{\boldsymbol{i}}$ e das frações a investir $\boldsymbol{x}_{\boldsymbol{i}}$.

Prova: De fato,

$$
\begin{aligned}
& \mathbf{M}(\mathbf{i}, \mathbf{j})=\sum_{1 \leq s \leq z}\left(\mathbf{r}_{\mathbf{p i s}}-\mathbf{t}\right)\left(\mathbf{r}_{\mathbf{p j s}}-\mathbf{t}\right)= \\
& \sum_{i=1}^{n}\left(\sum_{\substack{1 \leq s \leq z \\
X_{i s} \geq t,}} x_{i}^{2}\left(r_{i s}-t\right)^{2}\right)+\sum_{i=1}^{n}\left(x_{i}^{2} \sum_{\substack{1 \leq s \leq \mathrm{z}, X_{\mathrm{is}}<\mathrm{t},}}\left(r_{i s}-\mathrm{t}\right)^{2}\right)+ \\
& +\sum_{1 \leq i \leq j \leq n}^{n}\left(x_{i} x_{j} \sum_{\substack{1 \leq s \leq \mathrm{z}, \mathbf{X}_{\mathrm{is}}>\mathrm{t}, \mathrm{X}_{\mathrm{js}}>\mathrm{t}}}\left(\boldsymbol{r}_{i s}-\mathrm{t}\right)\left(\mathrm{r}_{\mathrm{js}}-\mathrm{t}\right)\right)+ \\
& +\sum_{1 \leq i \leq j \leq n}^{n}\left(x_{i} x_{j} \sum_{1 \leq s \leq \mathrm{z},}\left(\mathrm{r}_{\mathrm{is}}-\mathrm{t}\right)\left(\mathrm{r}_{\mathrm{js}}-\mathrm{t}\right)\right)+ \\
& \begin{array}{l}
X_{\text {is }}>t, \\
X_{\text {is }}<t
\end{array}
\end{aligned}
$$




$$
\begin{aligned}
& +\sum_{1 \leq i<j \leq n}^{n}\left(x_{i} x_{j} \sum_{\substack{1 \leq s \leq \mathrm{z}, \mathbf{X}_{\mathrm{is}<\mathrm{t}} \\
\mathrm{X}_{\mathbf{j s}}>\mathrm{t}}}\left(\boldsymbol{r}_{i s}-\mathbf{t}\right)\left(\mathbf{r}_{\mathbf{j s}}-\mathbf{t}\right)\right)+ \\
& +\sum_{1 \leq i<j \leq n}\left(x_{i} x_{j} \sum_{\substack{1 \leq s \leq \mathrm{z} \\
\mathbf{X}_{\mathrm{is}}<\mathrm{t}, \mathbf{X}_{\mathrm{js}}<\mathrm{t}}}\left(\mathbf{r}_{\mathrm{is}}-\mathbf{t}\right)\left(\mathbf{r}_{\mathrm{js}}-\mathbf{t}\right)\right) .
\end{aligned}
$$

A nova métrica do risco proposta a seguir, a métrica do risco estatística eficiente (EE), tem como base a matriz $\mathbf{M}$ em (5). Desta forma, o modelo de portfólio ótimo utilizando a métrica do risco estatística eficiente (EE) também poderia apresentar um modelo de otimização com solução por um algoritmo de otimização quadrático (QP). Porém, com o objetivo de permitir a avaliação de um maior número de interrelações entre os ativos, e também de permitir o aumento da dimensão do espaço objetivo da otimização, com a ideia de possibilitar uma busca por melhores resultados, são introduzidos $2 n^{2}-2 n+2$ parâmetros, relacionados a cada decomposição da matriz M, o que transforma o modelo de otimização em um modelo não linear (NLP) que pode convergir para uma solução ótima e que, apesar do maior número de parâmetros, apresenta um reduzido consumo computacional em relação ao algoritmo de otimização não suave (NSP) usualmente utilizado nos modelos de portfólios com métrica assimétrica do risco, que produzem apenas uma solução viável ou um ótimo local.

Definição: De forma a permitir a avaliação de um maior número de interrelações entre os ativos, aumentando a dimensão do espaço objetivo da otimização, para assim permitir a busca por melhores resultados, a métrica do risco estatística eficiente, denotada por $\mathbf{E E}$, é definida como:

$$
\mathbf{E E}=\lambda M^{-}-\gamma M^{+}+\sum_{1 \leq i<j \leq n}\left(\alpha_{i j} M_{i j}^{++}+\beta_{i j} M_{i j}^{+-}+\delta_{i j} M_{i j}^{-+}+\eta_{i j} M_{i j}^{--}\right)
$$

Apresentando $2 \mathrm{n}^{2}-2 \mathrm{n}+2$ parâmetros para estimação e onde $\boldsymbol{\lambda}$ e $\boldsymbol{\gamma}$ são positivos e $\boldsymbol{\alpha}_{\boldsymbol{i} \boldsymbol{j}}, \boldsymbol{\beta}_{\boldsymbol{i} \boldsymbol{j}}$, $\boldsymbol{\delta}_{\boldsymbol{i} \boldsymbol{j}}$ e $\boldsymbol{\eta}_{\boldsymbol{i} \boldsymbol{j}}$ são números reais finitos, e o risco pode ser calculado como $W^{\prime} \mathbf{E E} W$. O desmembramento da soma dos desvios quadrados e dos desvios quadrados cruzados dos retornos em relação à um alvo $\mathbf{t}$ pode ser estendida para qualquer grau de potência sem perda das propriedades apresentadas.

Como vantagens da nova métrica de risco $\mathbf{E E}$ se tem primeiro que por permitir a avaliação de um maior número de interrelações entre os ativos, inclusive considerando as interrelações entre os retornos acima e abaixo de um alvo t, e por dividir a estatística de dispersão utilizada para o cálculo do risco em vários subgrupos homogêneos, fornece um número maior de parâmetros a serem estimados, ou seja, permite avaliar um maior número de interrelações entre os ativos, aumentando a dimensão do espaço objetivo do modelo de otimização e, assim, possibilitando a busca por melhores resultados. E segundo que o modelo que utiliza a métrica de risco EE pode ser resolvido por um algoritmo de otimização não linear (NLP), que pode convergir para um ótimo global e que, embora contenha um número maior de parâmetros a serem estimados, requer reduzida capacidade de processamento em comparação ao algoritmo de otimização não suave (NSP) usualmente utilizados nos modelos com métricas assimétricas do risco, que fornecem apenas uma solução viável ou um ótimo local.

Utilizando a nova métrica do risco $\mathbf{E E}$ se pode representar o modelo de otimização como

$$
\operatorname{Min}_{X} V\left(R_{p}\right)=X^{\prime} \mathbf{E E} X
$$

Sujeito a: $E\left(R_{p}\right)=\widehat{R^{\prime}} X \geq R^{*}, x_{i} \geq 0$, e $\sum_{1=1}^{n} x_{i}=1$; 
sendo a minimização de $\mathbf{V}\left(\boldsymbol{R}_{\boldsymbol{p}}\right)$ realizada pela variação do vetor de pesos $\boldsymbol{X}$.

Onde o retorno esperado do portfólio pode ser calculado como $\boldsymbol{E}\left(\boldsymbol{R}_{\boldsymbol{p}}\right)=\widehat{\boldsymbol{R}^{\prime}} \boldsymbol{X}$ onde $\widehat{\boldsymbol{R}}$ é o vetor dos retornos esperados $\overline{\boldsymbol{r}}_{\mathrm{i}}$ dos ativos $\boldsymbol{A}_{\boldsymbol{i}}$ do portfólio em questão. Considerando como $\mathbf{R}^{*}$ o mínimo retorno requerido do portfólio.

Para resolver o modelo de otimização, se utiliza fórmulas empíricas análogas as do retorno médio e da métrica do risco do modelo EE. Considerando amostras com $\mathbf{z}$ observações de cada ativo $\boldsymbol{A}_{\boldsymbol{i}}$, se obtém:

$$
\begin{aligned}
& \hat{\bar{r}}=\left(\sum_{s=1}^{\mathrm{z}} \mathbf{r}_{\mathrm{is}}\right) / \mathbf{z} \\
& M_{i i}^{+}(i, i)=\sum_{\substack{1 \leq s \leq z \\
r_{i s}>t,}}\left(r_{i s}-t\right)^{2}, M^{+}(i, j)=0, \mathbf{i} \neq \mathbf{j} \\
& \mathbf{M}_{\mathrm{ii}}^{-}(\mathbf{i}, \mathbf{i})=\sum_{\substack{1 \leq s \leq \mathrm{z}, \mathbf{r}_{\mathrm{is}}<\mathrm{t},}}\left(\boldsymbol{r}_{i s}-\mathbf{t}\right)^{2}, M^{-}(\boldsymbol{i}, \boldsymbol{j})=\mathbf{0}, \mathbf{i} \neq \mathbf{j} \\
& \mathbf{M}_{\mathbf{i j}}^{++}(\mathbf{i}, \mathbf{j})=\mathbf{M}_{\mathbf{j i}}^{++}(\mathbf{j}, \mathbf{i})=\sum_{\substack{\mathbf{1} \leq \mathbf{s} \leq \mathbf{z}, \mathbf{r}_{\mathbf{i s}} \geq \mathbf{t} \\
\mathbf{r}_{\mathbf{j} \mathbf{s}} \geq \mathbf{t}}}\left(\boldsymbol{r}_{i s}-\mathbf{t}\right)\left(\mathbf{r}_{\mathbf{j s}}-\mathbf{t}\right) \text {, e 0 para as outras entradas; } \\
& \mathbf{M}_{\mathbf{i j}}^{+-}(\mathbf{i}, \mathbf{j})=\mathbf{M}_{\mathbf{j i}}^{+-}(\mathbf{j}, \mathbf{i})=\sum_{\substack{\mathbf{1} \leq \mathbf{s} \leq \mathbf{z}, \mathbf{r}_{\mathbf{i s}} \geq \mathbf{t},}}\left(\mathbf{r}_{\mathbf{i s}}-\mathbf{t}\right)\left(\mathbf{r}_{\mathbf{j s}}-\mathbf{t}\right), \text { e } 0 \text { para as outras entradas; } \\
& \mathbf{r}_{j s}<t \\
& \mathbf{M}_{\mathbf{i j}}^{-+}(\mathbf{i}, \mathbf{j})=\mathbf{M}_{\mathbf{j i}}^{-+}(\mathbf{j}, \mathbf{i})=\sum_{\substack{\mathbf{1} \leq \mathbf{s} \leq \mathbf{z}, \mathbf{r}_{\mathbf{i}}<\mathbf{t}, \mathbf{r}_{\mathbf{j} \mathbf{s}} \geq \mathbf{t}}}\left(\boldsymbol{r}_{\boldsymbol{i s}}-\mathbf{t}\right)\left(\mathbf{r}_{\mathbf{j s}}-\mathbf{t}\right), \text { e } 0 \text { para as outras entradas; } \\
& \mathbf{M}_{\mathbf{i j}}^{--}(\mathbf{i}, \mathbf{j})=\mathbf{M}_{\mathbf{j i}}^{--}(\mathbf{j}, \mathbf{i})=\sum_{\substack{\mathbf{1} \leq \mathbf{s} \leq \mathbf{z}, \mathbf{r}_{\mathbf{i s}}<\mathbf{t}, \mathbf{r}_{\mathbf{j} \mathbf{s}<\mathbf{t}}<\mathbf{t}}}\left(\mathbf{r}_{\mathbf{i s}}-\mathbf{t}\right)\left(\mathbf{r}_{\mathbf{j s}}-\mathbf{t}\right), \text { e } 0 \text { para as outras entradas. }
\end{aligned}
$$

\section{Novas Métricas para a Eficiência do Portfólio}

Para possibilitar uma melhor comparação entre o modelo de portfólio utilizando a métrica do risco $\mathbf{E E}$ e o modelo de portfólio utilizando a métrica do risco $\mathbf{E V}$, foi necessário determinar novas métricas para a eficiência do portfólio, em suplemento as definições de eficiência de portfólio apresentadas por Markowitz, H., M. (1952):

- Eficiência computacional - Quanto mais complexo é o modelo, para uma mesma base computacional e mesma tecnologia de programação, mais vagarosamente o algoritmo computacional resolve o modelo. Algoritmos mais velozes ou modelos que são solucionados por algoritmos menos complexos são mais eficientes computacionalmente.

- Eficiência da Solução - um modelo que é resolvido por um algoritmo que apresenta uma solução ótima global é mais eficiente na solução do que um modelo que é resolvido por um algoritmo que pode convergir para uma solução ótima global que é mais eficiente que um modelo que apresenta somente uma solução ótima local, que por sua vez e mais eficiente na solução do que um modelo que é resolvido por um algoritmo que apresenta apenas uma solução viável. Em geral, a eficiência computacional e a eficiência da solução costumam acontecer em conjunto. 
- Eficiência na diversificação - A diversificação pode reduzir, mas não eliminar o risco, e portfólios com alto retorno esperado não são necessariamente aqueles com a menor incerteza no retorno. Alguns modelos perdem diversificação de forma a conseguir retornos mais altos. Para balancear a comparação entre modelos distintos, foi definido o índice de diversificação (ID):

$\checkmark \quad$ ID $=1-\prod \boldsymbol{w}_{\boldsymbol{i}}$, onde $\boldsymbol{w}_{\boldsymbol{i}}$ é a fração do capital investida no ativo $\boldsymbol{A}_{\boldsymbol{i}}$. Para coerência do índice, quando algum $\boldsymbol{w}_{\boldsymbol{i}}<0.05$ este $\boldsymbol{w}_{\boldsymbol{i}}$ é desconsiderado no produtório.

Desta forma, o ID pode sempre ser calculado e quanto maior o ID, maior é a eficiência na diversificação.

- Eficiência padronizada do risco - Diferentes modelos de portfólio calculam diferentes métricas do risco. Para padronizar as métricas é preciso dividir o risco para um particular mínimo retorno requerido do portfólio pelo maior risco possível de ser alcançado no modelo de portfólio utilizado, considerando os ativos elegíveis para o portfólio, de forma a se ter uma métrica padronizada adimensional para a comparação entre diferentes modelos. Assim ainda se pode verificar qual o percentual do risco total do modelo é associado ao particular mínimo retorno requerido do portfólio. Usualmente, o maior risco possível ocorre, quando, no modelo de portfólio, é selecionado um mínimo retorno requerido suficientemente alto de forma que não ocorra diversificação no portfólio, considerando que quanto maior o retorno maior o risco. Assim, quanto maior o risco padronizado pior é a eficiência padronizada do risco.

- Eficiência do retorno - Pode-se comparar o retorno de diferentes modelos de portfólio por diversas formas. O retorno pode ser comparado por:

- O maior retorno, para o mesmo mínimo retorno requerido, em um único período;

- O maior retorno acumulado, para o mesmo retorno mínimo requerido, por um determinado período de evolução temporal previamente selecionados para uso na comparação da performance dos resultados dos modelos de otimização na análise ex-ante, ao final do período de holdout;

- Na análise ex-ante, o maior percentual de maiores retornos ao longo do período de holdout, ou seja, a prevalência de um modelo no período de holdout.

No investimento para um único período ou para um longo período, como definido por Markowitz, H., M. (1976), o investidor usa o portfólio ótimo, que é o portfólio dos ativos adquirido para o próximo período e reinvestido em cada novo período.

\section{Resultados da Comparação dos Modelos}

Por coerência dos modelos, quando se utiliza o retorno para um alvo $\mathbf{t}$, ou seja, o mínimo retorno aceitável (MRA) este foi feito igual ao mínimo retorno requerido (MRR) R*; que é utilizado para a construção das fronteiras eficientes.

Conforme a Seção 3.6, são considerados nesta comparação a performance dos resultados dos modelos de otimização pelo uso da métrica do risco EV do modelo de portfólio de Markowitz, H., M. (1952) e da nova métrica do risco estatística eficiente (EE) apresentada na Seção 4. 
As séries de dados dos ativos selecionados, conforme a Seção 3.1, são utilizadas para cada um dos dois períodos de séries de dados especificados na Seção 3.3 com os 100 primeiros retornos de cada série sendo feitos estacionárias, por diferença finita de primeira ordem, para utilização na análises ex-post. Os períodos considerados na análises ex-post são:

1. De 04 de janeiro de 2016 a 30 de maio de 2016, e;

2. De 02 de janeiro de 2018 a 28 de maio de 2018.

Para comparação dos resultados dos modelos deve-se primeiramente determinar o ponto de comparação entre os modelos conforme apresentado na Seção 3.4.

Para o período de 04 de janeiro de 2016 a 30 de maio de 2016, o Gráfico 2 a seguir apresenta o ponto de tangência da linha de alocação de capital (LAC), considerando um ativo livre de risco de aproximadamente $0,2 \%$, conforme a Seção 3.4, com a fronteira eficiente no modelo de portfólio com a métrica do risco $\mathbf{E V}$, variando de 0,000 a 0,4020. A tangência se dá no MRR igual à 0,2513 .

Gráfico 2: Tangência da LAC com a FE no período janeiro 2016 a maio de 2016.

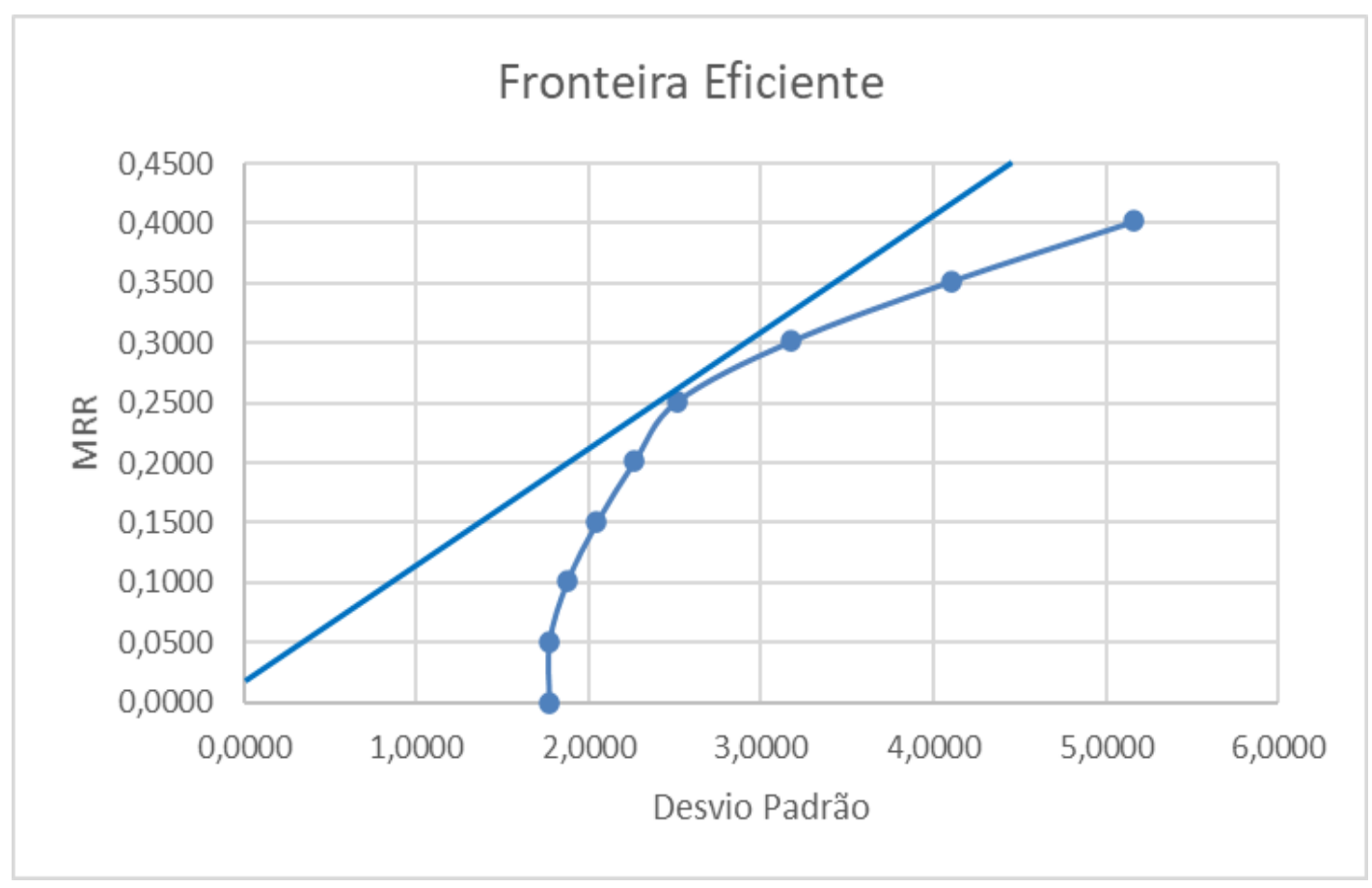

Fonte: Dados da Economática elaborado pelo autor.

No ponto de tangência especificado, 0,2513 , foi realizada a comparação da performance dos resultados dos modelos, em uma análise ex-post, utilizando as novas métricas para eficiência do portfólio, apresentada na Tabela 7 Painéis A, B, C e D, a seguir, com o significado do campo ordem igual a 1 como sendo o melhor resultado e ordem igual a 2 como sendo o pior resultado 
Tabela 7: Performance dos modelos - Novas métricas do risco (2016).

\begin{tabular}{|c|c|c|c|c|}
\hline Painel A: Eficiência Computacional & Método & \multicolumn{2}{|c|}{ Segundos } & Ordem \\
\hline E-V Markowitz & QP & \multicolumn{2}{|c|}{2,17} & 1 \\
\hline $\mathrm{EE}$ & NLP & \multicolumn{2}{|c|}{18,47} & 2 \\
\hline Painel B: Eficiência na Diversificação & \multicolumn{3}{|c|}{ ID } & Ordem \\
\hline E-V Markowitz & \multicolumn{3}{|c|}{$96,31 \%$} & 2 \\
\hline $\mathrm{EE}$ & \multicolumn{3}{|c|}{$99.61 \%$} & 1 \\
\hline Painel C: Eficiência no Retorno - Período Único & \multicolumn{3}{|c|}{ Retorno } & Ordem \\
\hline E-V Markowitz & \multicolumn{3}{|c|}{0.25} & 2 \\
\hline $\mathrm{EE}$ & \multicolumn{3}{|c|}{0.39} & 1 \\
\hline Painel D: Eficiência do Risco Padronizado & Risco & $\begin{array}{c}\text { Risco } \\
\text { Máximo }\end{array}$ & $\%$ & Ordem \\
\hline E-V Markowitz & 6.30 & 29.96 & $21 \%$ & 2 \\
\hline $\mathrm{EE}$ & 669.19 & $-684.05 *$ & $-98 \%$ & 1 \\
\hline
\end{tabular}

Fonte: Dados da Economática elaborado pelo autor.

*O modelo EE, com os coeficientes otimizados nas $2 n^{2}-2 n+2$ partições, pode apresentar um somatório do risco negativo.

Na análise da Tabela 12 Painéis A, B, C e D acima, utilizando as novas métricas para eficiência do portfólio como critérios adicionais para comparação dos portfólios, o modelo de portfólio com a métrica do risco EE tem o melhor resultado para o critério de eficiência na diversificação, de eficiência do retorno - período único e de eficiência do risco padronizado e o modelo de portfólio com a métrica do risco EV tem o melhor resultado para o critério de eficiência computacional.

No ponto de tangência especificado, 0,2513, também foi realizada a comparação da performance dos resultados dos modelos, em uma análise ex-ante, pela eficiência do retorno ao final do período de holdout, 28 de dezembro de 2017 . O Gráfico 3 a seguir apresenta a performance do resultado dos modelos considerando o início do período de holdout igual à $100 \%$, e inclui a comparação com o Ibovespa. A Tabela 8 abaixo apresenta as frações ótimas a investir em cada ativo e os valores dos modelos no final do período de houldout.

Gráfico 3: Eficiência do retorno ao final do período de holdout (2016 - 2017).

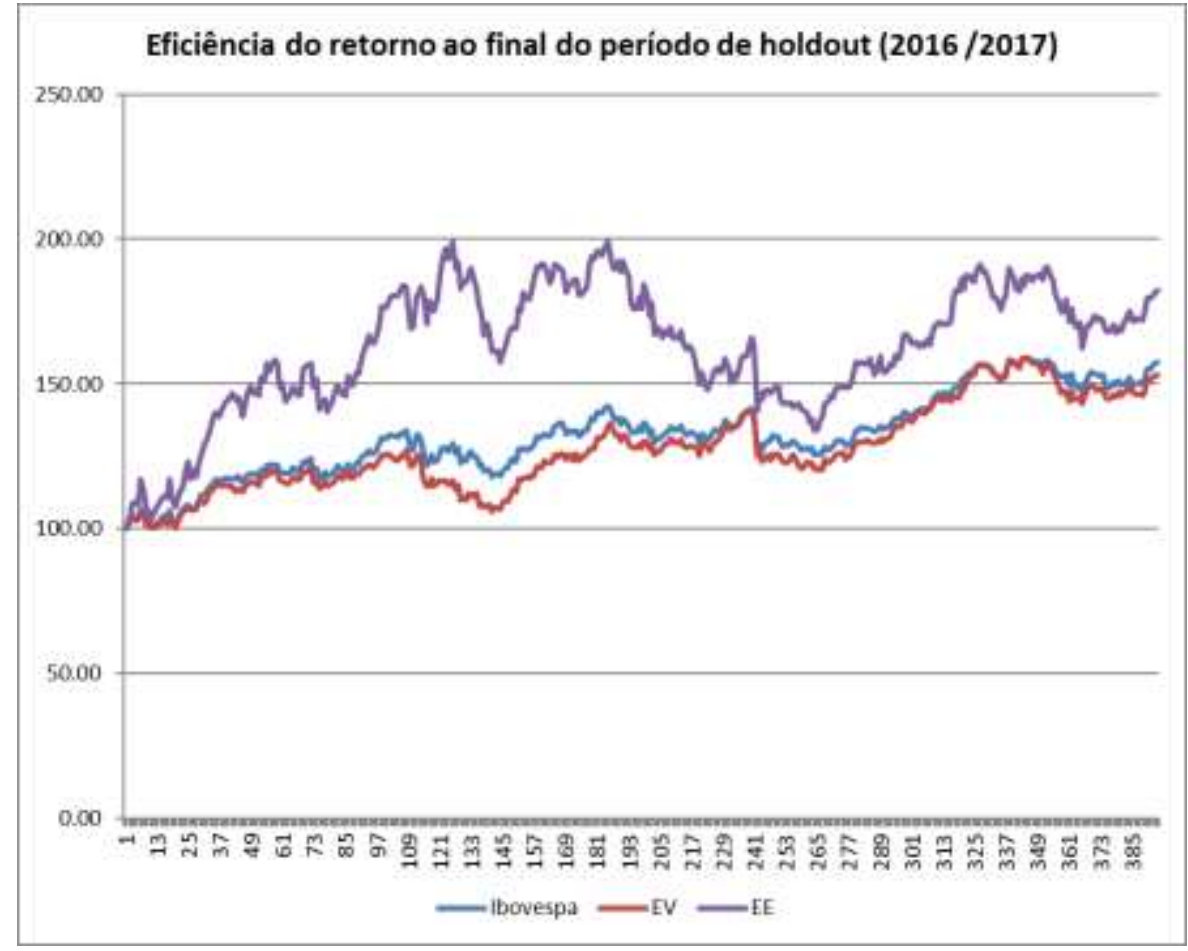

Fonte: Dados da Economática elaborado pelo autor. 
Tabela 8: Frações ótimas a investir e eficiência do retorno ao final do período de holdout (2016 - 2017)

\begin{tabular}{c|c|c|c|c|c|c|c|c|c|c|c}
\hline \multirow{2}{*}{ Modelos } & $\begin{array}{c}\text { Retorno ao Final do periodo de } \\
\text { holdout (2016/2017) }\end{array}$ & \multicolumn{10}{|c}{ Fracões ótima a investir } \\
\cline { 3 - 13 } & & ABEV3 & BBDC4 & BRKM5 & CMIG4 & GGBR4 & TSSA4 & PETR4 & CSNA3 & USIM5 & VALE3 \\
\hline Ibovespa & 157.62 & & & & & & & & & & \\
\hline EV & 153.32 & 0.3500 & 0.3107 & 0.0000 & 0.0000 & 0.0000 & 0.3393 & 0.0000 & 0.0000 & 0.0000 & 0.0000 \\
\hline EE & 182.54 & 0.0000 & 0.2500 & 0.0000 & 0.0000 & 0.2500 & 0.0000 & 0.2500 & 0.2500 & 0.0000 & 0.0000 \\
\hline
\end{tabular}

Fonte: Dados da Economática elaborado pelo autor.

Para o resultado de prevalência no período de holdout o modelo de portfólio com a métrica do risco EE teve $99 \%$ dos retornos diários acima do modelo de portfólio com a métrica do risco $\mathbf{E V}$ e $99 \%$ dos retornos diários acima do Ibovespa.

Para o período de 02 de janeiro de 2018 a 28 de maio de 2018, o Gráfico 6 a seguir apresenta o ponto de tangência da linha de alocação de capital (LAC), considerando um ativo livre de risco de aproximadamente $0,1 \%$, conforme a Seção 3.4, com a fronteira eficiente no modelo de portfólio com a métrica do risco $\mathbf{E V}$, variando de 0,0859 a 0,1672. A tangência se dá no MRR igual à 0,1468 .

Gráfico 4: Tangência da LAC com a FE no período janeiro 2018 a maio de 2018.

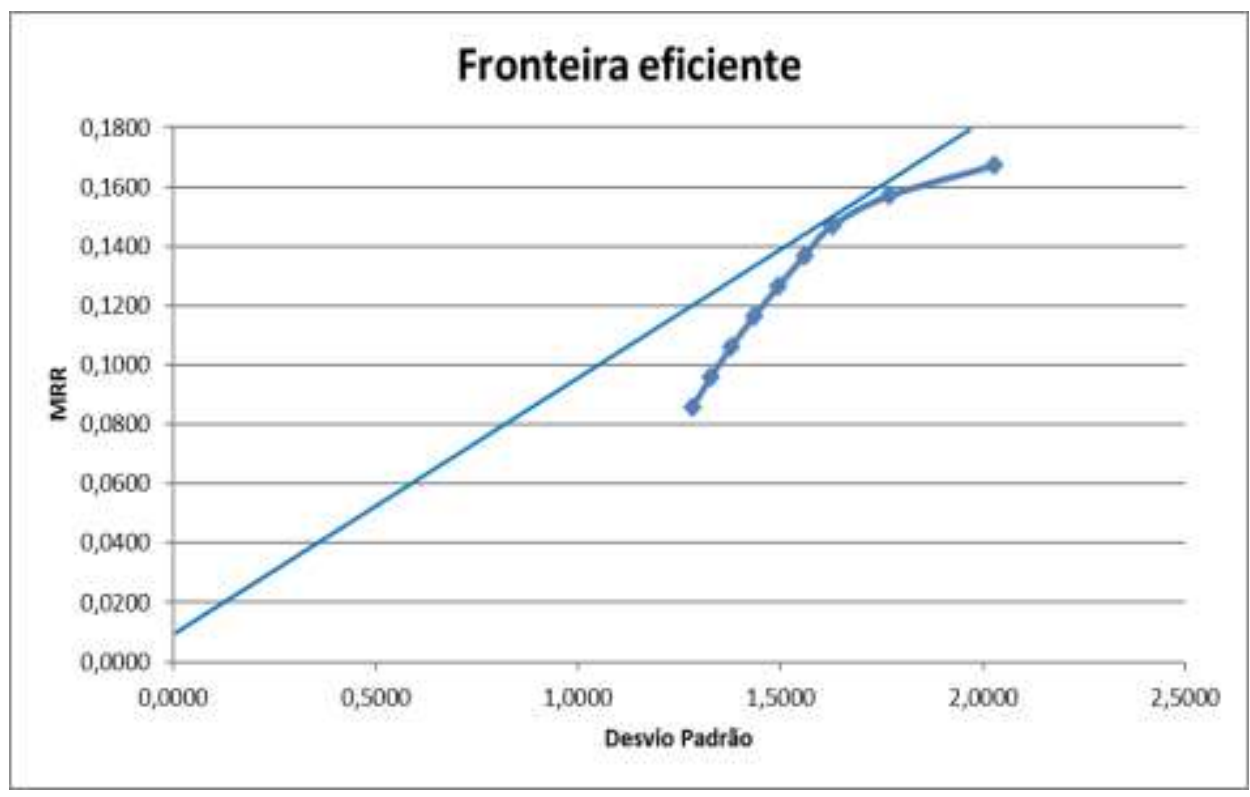

Fonte: Dados da Thompson-Reuters elaborado pelo autor.

No ponto de tangência especificado, 0,1468 , foi realizada a comparação da performance dos resultados dos modelos, em uma análise ex-post, utilizando as novas métricas para eficiência do portfólio, apresentada na Tabela 9 Painéis A, B, C e D, a seguir, com o significado do campo ordem igual a 1 como sendo o melhor resultado e ordem igual a 2 como sendo o pior resultado. 
Tabela 9: Performance dos modelos - Novas métricas do risco (2018).

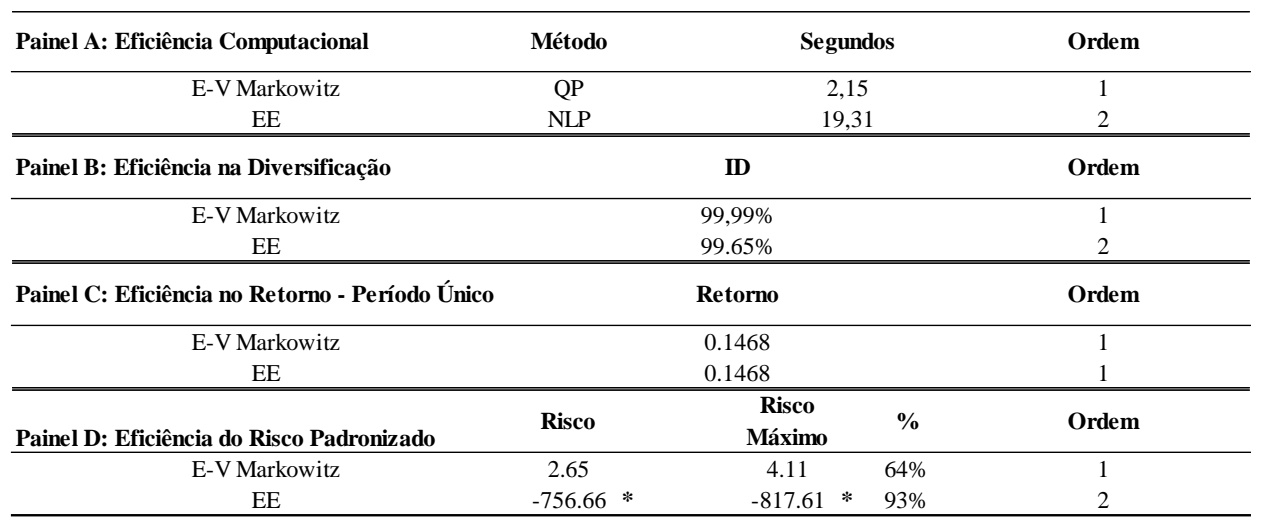

Fonte: Dados da Thompson-Reuters elaborado pelo autor.

*O modelo EE, com os coeficientes otimizados nas $2 n^{2}-2 n+2$ partições, pode apresentar um somatório do risco negativo.

Na análise da Tabela 9 Painéis A, B, C e D acima, utilizando as novas métricas para eficiência do portfólio como critérios adicionais para comparação dos portfólios, o modelo de portfólio com a métrica do risco EE tem o pior resultado nos critérios de eficiência computacional, de eficiência na diversificação e de eficiência do risco padronizado. O modelo de portfólio de portfólio com as métricas do risco EV e EE tem o mesmo resultado para o critério de eficiência do retorno - período único.

Ainda considerando o ponto de tangência especificado, 0,1468 , também foi realizada a comparação da performance dos resultados dos modelos, em uma análise ex-ante, pela eficiência do retorno ao final do período de holdout, que considera a extensão do holdout até 16 de setembro de 2020 incluindo o período de pandemia. O Gráfico 5 abaixo apresenta a performance do resultado dos modelos considerando o início do período de holdout igual à $100 \%$, e inclui a comparação com o Ibovespa. A Tabela 10 a seguir apresenta as frações ótimas a investir em cada ativo e os valores dos modelos no final do período de houldout.

Gráfico 5: Eficiência do retorno ao final do período de holdout (2018 - 2020).

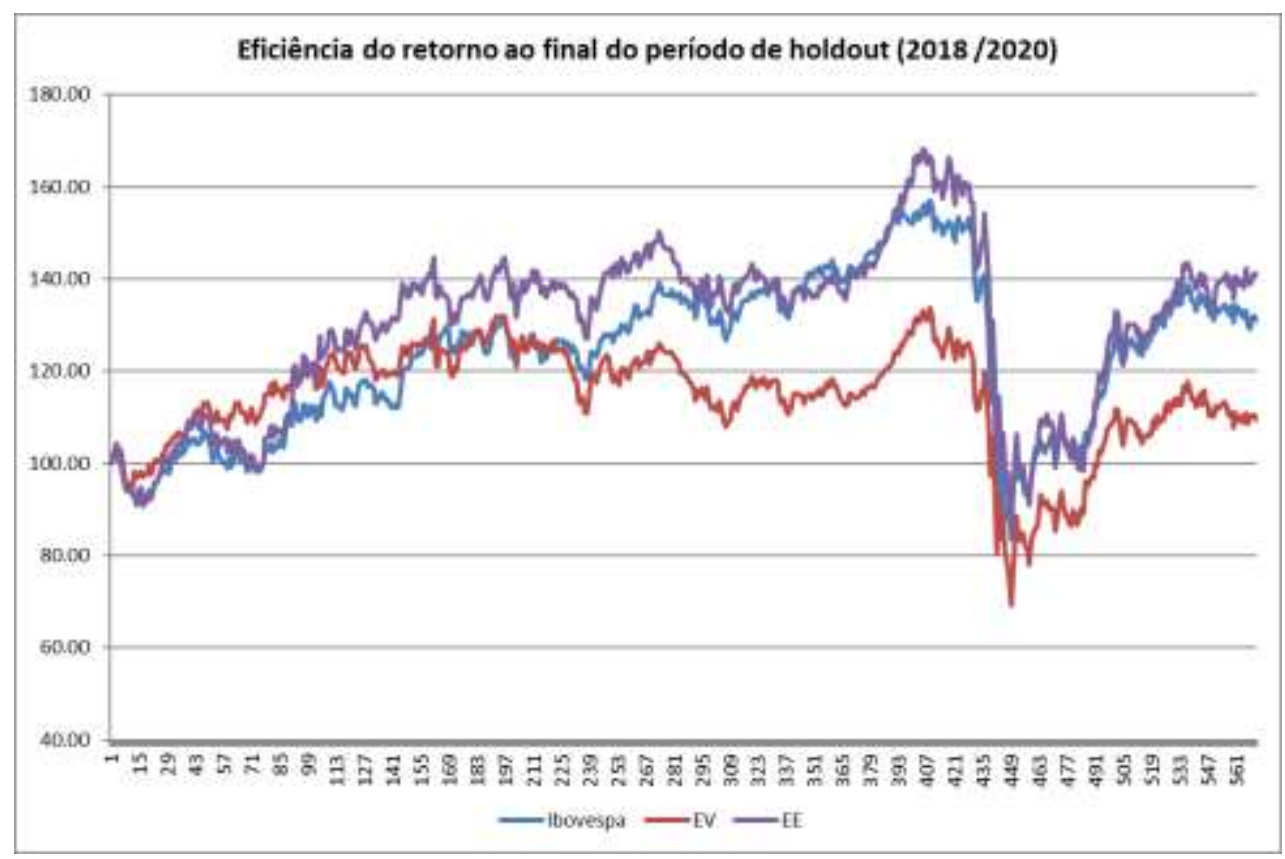

Fonte: Dados da Thompson-Reuters elaborado pelo autor. 
Tabela 10: Frações ótimas a investir e eficiência do retorno ao final do período de holdout (2018 - 2020).

\begin{tabular}{|c|c|c|c|c|c|c|c|c|c|c|c|}
\hline \multirow{2}{*}{ Modelos } & \multirow{2}{*}{$\begin{array}{c}\text { Retorno ao Final do período de } \\
\text { holdout (2018/2020) }\end{array}$} & \multicolumn{10}{|c|}{ Frações ótima a investir } \\
\hline & & $\overline{A B E 3}$ & $\overline{B B D C 4}$ & BRKM5 & CMIG4 & GGBR4 & ITSA4 & PETR4 & CSNA3 & USIM5 & VALE3 \\
\hline Ibovespa & 131.03 & & & & & & & & & & \\
\hline EV & 109.63 & 0.00 & 0.00 & 0.27 & 0.18 & 0.01 & 0.20 & 0.00 & 0.00 & 0.00 & 0.35 \\
\hline $\mathrm{EE}$ & 141.06 & 0.00 & 0.00 & 0.00 & 0.35 & 0.25 & 0.18 & 0.00 & 0.00 & 0.00 & 0.22 \\
\hline
\end{tabular}

Fonte: Dados Thompson-Reuters elaborado pelo autor.

Para o resultado de prevalência no período de holdout o modelo de portfólio com a métrica do risco EE teve $85 \%$ dos retornos diários acima do Ibovespa e $84 \%$ dos retornos diários acima do modelo de portfólio com a métrica do risco EV.

\section{Análise da Comparação dos Modelos}

$\mathrm{Na}$ Seção 6, na análise da performance dos resultados dos modelos de portfólio com a métrica do risco EV, EE e do Ibovespa, é importante notar que o Ibovespa é reavaliado (calibrado) quadrimestralmente e atualizado diariamente. Os modelos utilizando as métricas do risco $\mathbf{E V}$ e $\mathbf{E E}$ permaneceram com a avaliação dos percentuais ótimos a investir em cada ativo constantes ao longo dos períodos de holdout considerados.

Na Seção 6, no MRR considerado para comparação dos modelos, o modelo utilizando a métrica do risco EE superou o Ibovespa e o modelos utilizando a métrica do risco $\mathbf{E V}$, nas duas séries consideradas e de forma consistente, nos retornos diários ao longo do período de holdout e na eficiência do retorno ao final do período de holdout, sendo que a performance dos resultados do modelo $\mathbf{E E}$ foi melhor no primeiro período considerado.

No primeiro período de holdout o modelo de portfólio com a métrica do risco EE teve 99\% dos retornos diários acima do Ibovespa e $99 \%$ dos retornos diários acima do modelo de portfólio com a métrica do risco EV. Na eficiência do retorno ao final do período de holdout o modelo de portfólio com a métrica do risco EE teve um retorno de $182,54 \%$ contra os retornos de 157,62\% do Ibovespa e de 153,32\% do modelo de portfólio com a métrica do risco EV.

No segundo período de holdout o modelo de portfólio com a métrica do risco EE teve 85\% dos retornos diários acima do Ibovespa e $84 \%$ dos retornos diários acima do modelo de portfólio com a métrica do risco EV. Na eficiência do retorno ao final do período de holdout o modelo de portfólio com a métrica do risco EE teve um retorno de 141,06\% contra os retornos de 131,03\% do Ibovespa e de 109,63\% do modelo de portfólio com a métrica do risco EV.

$\mathrm{Na}$ análise da performance das novas métrica para eficiência do portfólio, no MRR considerado para comparação dos modelos, o modelo EV, modelo quadrático, sem assimetria, minimizando o desvio para o retorno médio, tem nos dois períodos melhor resultado na eficiência computacional.

No primeiro período de análise o modelo de portfólio com a métrica do risco EE, não linear, assimétrico, analisando um maior número de interrelações entre os ativos, apresenta uma melhor eficiência do retorno em um único período, uma melhor eficiência do retorno ao final do período de holdout, $99 \%$ dos retornos diários acima do Ibovespa e 99\% dos retornos diários acima do modelo de portfólio com a métrica do risco $\mathbf{E V}$, uma melhor eficiência na diversificação e uma melhor eficiência no risco padronizado. Apesar do pior desempenho no resultado para eficiência computacional, o modelo de portfólio com a métrica do risco EE, pelo seu melhor desempenho nos retornos em um único período, do retorno ao final do período de holdout, nos retornos diários ao longo do período de holdout e melhor diversificação, se apresenta como um substituto vantajoso em relação aos modelos EV, inclusive por utilizar uma métrica assimétrica do risco pois segundo Kang, T., Brorsen B.W. \& Adam, B.D. (1996) as distribuições dos ativos geralmente não se ajustam a um modelo simétrico sendo, geralmente, assimétricas e leptocúrticas. 
No segundo período de análise os modelos de portfólio com a métrica do risco $\mathbf{E V}$ e $\mathbf{E E}$ tem a mesma eficiência do retorno em um único período, e o modelo $\mathbf{E E}$ tem os melhores resultados na eficiência do retorno ao final do período de holdout, 85\% dos retornos diários acima do Ibovespa e $84 \%$ dos retornos diários acima do modelo de portfólio com a métrica do risco EV. O modelo de portfólio com a métrica do risco EE tem os piores resultados na eficiência computacional e na eficiência do risco padronizado e praticamente o mesmo desempenho na eficiência da diversificação.

Apesar do pior desempenho no resultado para eficiência computacional e para eficiência do risco padronizado e igual resultado ao modelo de portfólio com a métrica do risco $\mathbf{E V}$ para a eficiência do retorno - período unico, o modelo de portfólio com a métrica do risco $\mathbf{E E}$, pelo seu melhor desempenho nos retornos diários ao longo do período de holdout e no retorno ao final do período de holdout, ainda se apresenta como um substituto vantajoso em relação aos modelos de portfólio com a métrica do risco $\mathbf{E V}$, inclusive, como já foi comentado, por utilizar uma métrica assimétrica do risco pois segundo Kang, T., Brorsen B.W. \& Adam, B.D. (1996) as distribuições dos ativos geralmente não se ajustam a um modelo simétrico sendo, geralmente, assimétricas e leptocúrticas.

Na Seção 3.3, se verifica que o primeiro período de holdout, análise ex-ante, apresenta, para os ativos considerados nas análises, maiores valores de coeficiente de variação e de volatilidade o que pode ser a explicação dos melhores resultados do modelo de portfólio com a métrica do risco $\mathbf{E E}$ no primeiro período de holdout, por permitir que o modelo de portfólio com a métrica do risco $\mathbf{E E}$, com o desmembramento de sua métrica do risco e utilizando $2 n^{2}-2 n+2$ coeficientes, tenha um melhor desempenho na percepção das incertezas inerentes ao processo de seleção de portfólios. Ainda na Seção 3.3, se verifica que o primeiro período de análise ex-post apresenta, para os ativos considerados nas análises, maiores valores de coeficiente de variação e de volatilidade o que pode ser a explicação dos melhores resultados do modelo de portfólio com a métrica do risco EE para as novas métricas de eficiência do portfólio no primeiro período de análise ex-post também por permitir que o modelo de portfólio com a métrica do risco $\mathbf{E E}$, com o desmembramento de sua métrica do risco e utilizando $2 n^{2}-2 n+2$ coeficientes, tenha um melhor desempenho na percepção das incertezas inerentes ao processo de seleção de portfólios.

Assim, o modelo de portfólio com a métrica do risco EE, de forma geral e consistente, pode se apresentar como uma alternativa viável e vantajosa para solução de modelos de otimização, tanto para métricas do risco simétricas como assimétricas, principalmente para períodos de mercado caracterizados por maior volatilidade (desvio padrão).

\section{Conclusão}

A principal contribuição original e relevante deste artigo foi a definição de uma nova métrica do risco, a métrica do risco estatística eficiente (EE) apresentada na Seção 4 e com resultados na Seção 6 deste trabalho. A métrica do risco $\mathbf{E E}$ considera um maior número de interrelações entre os ativos, inclusive considerando os retornos acima e abaixo de um alvo $\mathbf{t}$, quando divide a métrica assimétrica do risco utilizada para o cálculo do risco em $2 n^{2}-2 n+2$ subgrupos homogêneos fornecendo um número maior de parâmetros a serem estimados, ou seja, aumentando a dimensão do espaço objetivo do modelo de otimização e, assim, possibilitando a busca por melhores resultados. A métrica assimétrica do risco EE pode ser resolvida por um algoritmo de otimização não linear (NLP), que pode convergir para um ótimo global e que, embora contenha um número maior de parâmetros a serem estimados, requer reduzida capacidade de processamento em comparação ao algoritmo de otimização não suave (NSP), usualmente utilizado pelas métricas assimétricas do risco que consideram retornos acima e abaixo de um alvo $\mathbf{t}$, que fornecem apenas um ótimo local ou uma solução viável.

Para comparação da eficiência entre diferentes métricas do risco e diferentes modelos de seleção de portfólios foram definidas na Seção 5 as novas métricas para a eficiência do portfólio que também são uma contribuição original e relevante deste artigo. 
O artigo apresenta a nova métrica do risco estatística eficiente, que demonstrou melhores resultados nos dados utilizados e novas métricas para a eficiência do portfólio. Apresenta assim uma importante contribuição para a extensão das métricas do risco nos modelos de seleção de portfólio e para a comparação da eficiência entre diferentes modelos de seleção de portfólio.

\section{Futura Linha de Pesquisa}

É importante realizar um planejamento de experimentos, com um maior número de análises, de forma que se possa garantir, para as diversas situações de mercado, quando o modelo de otimização com a métrica assimétrica do risco $\mathbf{E E}$, de forma geral, se apresenta como uma alternativa viável e vantajosa em relação ao modelo de otimização EV e para solução de modelos de otimização de portfólios com métricas do risco simétricas como assimétricas.

\section{Agradecimentos}

À professora Sônia Maria da Fonseca pelo apoio e incentivo na realização do meu doutorado como também ao longo de toda minha carreira profissional. Ao professor Marcelo Cabús Klötzle e à Erick Meira pela aquisição de dados pelo convênio da PUC-Rio com a Thompson-Reuters. Ao professor Luiz Eduardo Brandão e à Jefferson Costa Dias pela aquisição de dados pelo convênio da PUC-Rio com a Economática.

\section{Referências}

Abensur, E.O., Moreira, D.F. \& Faria A.C.R. (2020). Geometric Brownian Motion: an Alternative to High-Frequency Trading for Small Investors. Independent Journal of Management \& Production (IJM\&P), ISSN: 2236-269X. DOI: 10.14807/ijmp.v11i3.1114.

Allen, D., Lizieri, C. \& Satchell, S. (2019). In Defense of Portfolio Optimization What If We Can Forecast? https://ssrn.com/abstract=3373594.

Arce, P., E., B., Arce, A., S., E. \& Carneiro A., A., F., M. (2014). Modelo de Otimização de Contratos de Potência para o Suprimento do Sistema Elétrico Paraguaio com Itaipu. Anais do V Simpósio Brasileiro de Sistemas Elétricos, Foz do Iguaçu - PR, Brasil. 22-25/04/2014, ISSN 2177-6164.

Aria, M. \& Cuccurullo, C. (2017). Bibliometrix: An R-tool for comprehensive science mapping analysis, Journal of Informetrics, 11(4), pp. 959-975, Elsevier, DOI: 10.1016/j.joi.2017.08.007.

Aziz, N. S. A., Spyridon V., S. \& Hasim, H. M. (2019). Evaluation of multivariate GARCH models in an optimal asset allocation framework. North American Journal of Economics and Finance, 47 (2019) 568-596.

Ban, G., Karoui, N. E. \& Lim, A. E. B. (2016). Machine Learning and Portfolio Optimization. Published online in Management Science Articles in Advance, 21 Nov 2016. http://dx.doi.org/10.1287/mnsc.2016.2644.

Banihashemi, S., Azarpour, A. M. \& Navvabpour, H. (2016). Portfolio Optimization by Mean-Value at Risk Framework. Applied Mathematics \& Information Sciences, 10, No. 5, 1935-1948 (2016).

Bawa, V.S. \& Lindenberg, E.B. (1977). Capital Market Equilibrium in a Mean-lower Partial Moment Framework. Journal of Financial Economics, 5:189-200.

Becker, F., Gurtler, M. \& Hibbelin M. (2015). Markowitz versus Michaud Portfolio Optimization Strategies Reconsidered. (2015), European Journal of. Finance, 21, pp. 269-291.

Begoña F. (2016). Bootstrap estimation of the efficient frontier. Computer Management Science, (2016) 13:541-570 DOI 10.1007/s10287-016-0257-2.

Bianchi, D. \& Guidoliny, M. (2013). Can Long-Run Dynamic Optimal Strategies Outperform Fixed-Mix Portfolios? Evidence from Multiple Data Sets. http://ssrn.com/abstract=2353761.

Bianchi, M. L. \& Tassinari, G. L. (2018). Forward-looking portfolio selection with multivariate non-Gaussian models and the Esscher transform. arXiv: $1805.05584 \mathrm{v} 2$ [q-fin.PM] 25 May 2018.

Black, F., Jensen, C., M. \& Scholes, M. (1972). The Capital Asset Pricing Model: Some Empirical Tests, pp. 79-121 in M. Jensen ed., Studies in the Theory of Capital Markets. New York: Praeger Publishers, 1972.

Brito, N.R.O. (2006). Alocação de Ativos em Private Banking. Editor: Bookman, ISBN: 9788560031085.

Bulai, V. \& Horobet, A. (2018) A portfolio optimization model for a large number of hydrocarbon exploration projects. Proceedings of the International Conference on Business Excellence, vol. 12, issue. DOI: https://doi.org/10.2478/picbe-2018-0017. Published online: 15 Jun 2018.

Caporin, M. (2014). A Survey on the Four Families of Performance Measures. Journal of Economic Surveys, (2014) Vol. 28, No. 5, pp. 917-942.

Christopher W. \& Millery I. Y. (2017). Optimal Control of Conditional Value-at-Risk in Continuous Time. arXiv:1512.05015v3 [math.OC] 23 Jan 2017. 
DeMiguel, V., Garlappi, L. \& Uppal, R., (2009). Optimal Versus Naive Diversification: How Inefficient is the 1/N Portfolio Strategy? The Review of Financial Studies / v 22 n 5 2009. doi:10.1093/rfs/hhm075.

DeMiguel, V., Martin-Utrera, A. \& Nogales, F. J. (2013). Size matters: Optimal calibration of shrinkage estimators for portfolio Selection. Journal of Banking \& Finance, 37 (2013) 3018-3034.

Domingues, M.A. (2018). Mapeamento da Ciência com o Pacote R Bibliometrix: Uma aplicação no estudo de Empreendedorismo Acadêmico. Proceeding of ISTI/SIMTEC - ISSN: 2318-3403, DOI: 10.7198/S2318-3403201800010033, Aracaju/SE - 19 a 21/09/ 2018, vol. 9, n. 1, p. $287-294$.

Du, Z. \& Pei, P. (2020). Backtesting Portfolio Value-at-Risk with Estimated Portfólio Weights. Journal of. Time Series. Analysis, 41: 605-619 (2020). Published online 06April 2020 inWileyOnline Library (wileyonlinelibrary.com) DOI: 10.1111/jtsa.12524.

Edirisinghe, N.C.P.\& Zhang, X. (2010). Input/output selection in DEA under expert information with application to financial markets. European Journal of Operational Research 207 (2010) 1669-1678.

Fan, J., Zhang, J. \& Yu K. (2012). Vast Portfolio Selection with Gross-Exposure Constraints, Journal of the American Statistical Association, 107:498, 592606.

Fortin, J. \& Hlouskova, J. (2015). Downside loss aversion:Winner or loser? Math Meth Oper Res, (2015) 81:181-233. DOI 10.1007/s00186-015-0493-1.

Fishburn, P.C. (1977). Mean-Risk Analysis with Risk Associated with Below-Target Returns. The American Economic Review, vol. 67, n.o. 2 (Mar., 1977), pp. $116-126$.

Gil, A. C. (2008). Métodos e técnicas de pesquisa social. ISBN 978-85-224-5142-5. Ed. São Paulo. Atlas. 2008.

Glensk, B. \& Madlener, R. (2018). Fuzzy Portfolio Optimization of Power Generation Assets. November 2018, Energies 11(11): 3043. DOI: 10.3390/en11113043. License CC BY 4.0

Hilario-Caballero, A., Garcia-Bernabeu A, Salcedo, J., V. \& Vercher, M. (2020). Tri-Criterion Model for Constructing Low-Carbon Mutual Fund Portfolios: A Preference-Based Multi-Objective Genetic Algorithm Approach. International Journal of Environmental Research and. Public Health, 2020, 17, 6324; doi:10.3390/ijerph17176324.

Holthausen D.M. (1981). A Risk-Return Model with Risk and Return Measured as Deviations from a Target Return. American Economic Review, American Economic Association; vol. 71(1), pp. 182-88, March 1981.

Kaczmarek, K., Dymova, L. \& Sevastjanov, P. (2020). A Simple View on the Interval and Fuzzy Portfolio Selection Problems. Entropy, 2020, 22, 932; doi:10.3390/e22090932

Kalayci C.B.; Ertenlice, O. \& Akbaya, M.A. (2019) A comprehensive review of deterministic models and applications for mean-variance portfolio optimization. Published 2019, Computer Science, Expert Systems with Applications, Volume 125, 1 July 2019, Pages 345-368. https://doi.org/10.1016/j.eswa.2019.02.011.

Kang, T., Brorsen B.W. \& Adam, B.D. (1996). The mean-separated target deviations risk model. Journal of Economics and Business, 48, pp. 47-66. Temple University.

Kolm, P. N., Tütüncü, R. \& Fabozzi, F. J. (2014). 60 Years of portfolio optimization: Practical challenges and current trends. European Journal of Operational Research 234 (2014) 356-371.

Kwong, R. \& Low, Y. (2015). Vine copulas: Modeling systemic risk and enhancing higher-moment portfolio optimization. http://ssrn.com/abstract=2259076.

Lai S., Tao, Y., Qiu, J. \& Zhao, J. (2019). Gas Generation Portfolio Management Strategy Based on Financial Derivatives: Options. 2019 9th International Conference on Power and Energy Systems (ICPES), Perth, Australia, 2019, pp. 1-6, DOI: 10.1109/ICPES47639.2019.9105461.

Lasdon, L. S., Waren, A., D., Jain, A. \& Ratner, M., W. (1975). Design and testing of a generalized reduced gradient code for nonlinear optimization, Case Western Reserve University, prepared for: Office of Naval Research - 1975.

Leal, R. P. C. \& Mendes, B. V. M. (2013). Assessing the effect of tail dependence in portfolio allocations. Applied Financial Economics, 2013 Vol. 23, No. 15, 1249-1256, http://dx.doi.org/10.1080/09603107.2013.804160.

Li, X. \& Qin, Z. (2014). Interval portfolio selection models within the framework of uncertainty theory. Economic Modelling 41 (2014) 338-344.

Lin, P. (2012). Portfolio Optimization and Risk Measurement Based on Non-Dominated Sorting Genetic Algorithm. JournalL of IindustrialL and Management Optimization, Volume 8, Number 3, August 2012. doi:10.3934/jimo.2012.8.549.

Liu, Y., Zhang, W. \& Zhang, P. (2013). A multi-period portfolio selection optimization model by using interval analysis. Economic Modelling, 33 (2013) 113119.

Mahdi, M., Masoud, M. \& Alireza A., K., (2020). Development of an efficient cluster-based portfolio optimization model under realistic market conditions. Empirical Economics, (2020), 59:2423-2442. https://doi.org/10.1007/s00181-019-01802-5.

Markowitz, H., M. (1952). Portfolio Selection. The Journal of Finance, vol. 7, n. 1, Mar., pp. 77-9, 1952.

Markowitz, H., M. (1956). The optimization of the quadratic function subject to linear constraints. Naval Res. Log. Quarterly 3, pp. 111-133, 1956.

Markowitz, H., M. (1959). Portfolio Selection, Efficiency Diversification of Investments. Cowles Foundation Monograph 16, Yale University Press, 1959.

Markowitz, H., M. (1976). Investment for the Long Run: New Evidence for an Old Rule. The American Finance Association, The Journal of Finance, vol. 31, n. 5, pp. 1273-1286, December 1976. 
Markowitz, H., M. (1987). Mean- Variance Analysis in Portfolio Choice and Capital Markets. By Harry M. Markowitz. Oxford, UK: Basil Blackwell, 1987. Pp. $\mathrm{xi}+387$.

Markowitz, H., M. (1991). Foundations of Portfolio Theory. The Journal of Finance, vol. 46, n. 2, Jun, 1991, pp. 469-477.

Owen W., S. (2015). Foreign Currency Exposure within Country Exchange Traded Funds. Frontiers in Finance, Volume 1, 2015.

Post, T., Karabati, S. \& Arvanitis, S. (2018). Portfolio optimization based on stochastic dominance and empirical likelihood. Journal of Econometrics, 206 (2018) $167-186$.

Pritchard, A. (1969). Statistical bibliography or bibliometrics? https://www-scopus.ez20.periodicos.capes.gov.br/search/form.uri?display=basic. Journal of Documentation, v. 24, n. 4, p. 348-349, 1969. SCOPUS.

Rom, B.M. \& Ferguson K.W. (1993). Post-Modern Portfolio Theory Comes of Age. Brian M. Rom and Kathleen W. Ferguson. The Journal of Investing Winter, 1993, 2 (4) 27-33; DOI: https://doi.org/10.3905/joi.2.4.27.

Rubinstein, M. (2002) Markowitz's Portfolio Selection A Fifty-Year Retrospective. The Journal of Finance, vol. LVII, n. 3, June 2002.

Ruidi S. \& Yue C. (2020). A New Adaptive Entropy Portfolio Selection Model. Entropy 2020, 22, 951; doi:10.3390/e22090951.

Salah, H., B., Chaouch, M., Gannoun, A., Peretti, C. \& Trabelsi, A. (2018). Mean and median-based nonparametric estimation of returns in mean-downside risk portfolio frontier. Ann Oper Res., (2018) 262:653-681. https://doi.org/10.1007/s10479-016-2235-z.

Santamaría, R., Aguarón, J. \& Moreno-Jiménez, J. M. (2020). A multicriteria approach based on Analytic Hierarchy Process and compromise programming in portfolio selection. J Multi-Crit Decis Anal. 2020, 27, 141-146. DOI: 10.1002/mcda.1699.

Scherer, B. (2002). Portfolio Construction and Risk Budgeting. Risk Books, a division of the Risk Waters Group, ISBN 189933244 8. $2002 \mathrm{a}$.

Scherer, B. (2010). A New Look at Minimum Variance Investing. https://ssrn.com/abstract=1681306.

Solvers Reference Guide, Frontline (2020). User Guide copyright 2020 by Frontline Systems, Inc.

Sui, Y., Hu, J. \& Ma, F. (2020). A Mean-Variance Portfolio Selection Model with Interval-Valued Possibility Measures. Mathematical Problems in Engineering, Volume 2020, Article ID 4135740, 12 pages. https://doi.org/10.1155/2020/4135740.

Tang, L. \& Ling, A. (2014). Closed-Form Solution for Robust Portfolio Selection with Worst-Case CVaR Risk Measure. Mathematical Problems in Engineering, Volume 2014, Article ID 494575, 9 pages. http://dx.doi.org/10.1155/2014/494575.

Tejeda, C., Gallardo, C., Domínguez, M. et al. (2017). Using wind velocity estimated from a reanalysis to minimize the variability of aggregated wind farm production over Europe. Wind Energy, 2017, Volume 21, Issue 3. https://doi.org/10.1002/we2153

Tobin, J. (1958a). Estimation of relationships for limited dependent variables. Econometrica. The Econometric Society, 26(1), pp. 24-36, 1958a, DOI: 10.2307/1907382. JSTOR 1907382.

Tobin, J. (1958b). Liquidity Preference as Behavior Towards Risk. Review of Economic Studies, 25.1, pp. 65-86, 1958b, DOI: 10.2307/2296205.

Wang, C. D., Chen Z., Lian Y. \& Chen. M. (2020). Asset selection based on high frequency Sharpe ratio. Journal of Econometrics (2020), https://doi.org/10.1016/j.jeconom.2020.05.007.

Xinxin, J. \& Jianjun, G. (2016). Extensions of Black-Litterman portfolio optimization model with downside risk measure. 978-1-4673-9714-8/16/\$31.00@ 2016 IEEE.

Yu, J., Chiou, W. P. \& Mu, D. (2015). A linearized value-at-risk model with transaction costs and short selling. European Journal of Operational Research 247 (2015) 872-878. 